\title{
Voltage-Independent SK-Channel Dysfunction Causes Neuronal Hyperexcitability in the Hippocampus of Fmr1 Knock-Out Mice
}

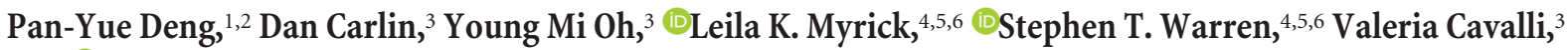 \\ and $\odot$ Vitaly A. Klyachko ${ }^{1,2}$ \\ ${ }^{1}$ Departments of Cell Biology and Physiology, ${ }^{2}$ Biomedical Engineering, ${ }^{3}$ Neuroscience, Washington University School of Medicine, St. Louis, Missouri \\ 63110, and Departments of ${ }^{4}$ Human Genetics, ${ }^{5}$ Biochemistry, and ${ }^{6}$ Pediatrics, Emory University School of Medicine, Atlanta, Georgia 30322
}

\begin{abstract}
Neuronal hyperexcitability is one of the major characteristics of fragile X syndrome (FXS), yet the molecular mechanisms of this critical dysfunction remain poorly understood. Here we report a major role of voltage-independent potassium $\left(\mathrm{K}^{+}\right)$-channel dysfunction in hyperexcitability of CA3 pyramidal neurons in Fmr1 knock-out (KO) mice. We observed a reduction of voltage-independent small conductance calcium $\left(\mathrm{Ca}^{2+}\right)$-activated $\mathrm{K}^{+}$(SK) currents in both male and female mice, leading to decreased action potential (AP) threshold and reduced medium afterhyperpolarization. These SK-channel-dependent deficits led to markedly increased AP firing and abnormal input- output signal transmission of CA3 pyramidal neurons. The SK-current defect was mediated, at least in part, by loss of FMRP interaction with the SK channels (specifically the SK2 isoform), without changes in channel expression. Intracellular application of selective SK-channel openers or a genetic reintroduction of an N-terminal FMRP fragment lacking the ability to associate with polyribosomes normalized all observed excitability defects in CA3 pyramidal neurons of Fmr1 KO mice. These results suggest that dysfunction of voltage-independent SK channels is the primary cause of CA3 neuronal hyperexcitability in Fmr1 KO mice and support the critical translation-independent role for the fragile $\mathrm{X}$ mental retardation protein as a regulator of neural excitability. Our findings may thus provide a new avenue to ameliorate hippocampal excitability defects in FXS.
\end{abstract}

Key words: action potential; excitability; FMRP; presynaptic function; SK channels; threshold

Significance Statement

Despite two decades of research, no effective treatment is currently available for fragile X syndrome (FXS). Neuronal hyperexcitability is widely considered one of the hallmarks of FXS. Excitability research in the FXS field has thus far focused primarily on voltage-gated ion channels, while contributions from voltage-independent channels have been largely overlooked. Here we report that voltage-independent small conductance calcium-activated potassium (SK)-channel dysfunction causes hippocampal neuron hyperexcitability in the FXS mouse model. Our results support the idea that translation-independent function of fragile X mental retardation protein has a major role in regulating ion-channel activity, specifically the SK channels, in hyperexcitability defects in FXS. Our findings may thus open a new direction to ameliorate hippocampal excitability defects in FXS.

\section{Introduction}

Fragile X syndrome (FXS) is the most common cause of inherited intellectual disability and the leading genetic cause of autism (Santoro et al., 2012). This disorder arises from loss-of-function mutations in a single gene, Fmr1, encoding fragile X mental re-

\section{Received June 25, 2018; revised Oct. 8, 2018; accepted 0ct. 25, 2018}

P.-Y.D., S.T.W., V.C., and V.A.K. designed research; P.-Y.D., D.C., Y.M.O., and L.K.M. performed research; P.-Y.D. and V.A.K. contributed unpublished reagents/analytic tools; P.-Y.D., D.C., and Y.M.O. analyzed data; P.-Y.D. and V.A.K. wrote the paper.

This work was supported by National Institute of Neurological Disorders and Stroke (NINDS) Grant R01 NS089449 to V.A.K. and by NINDS and National Institute of Child Health and Human Development Grant U54 NS091859 to S.T.W. tardation protein (FMRP). FXS is associated with cognitive, behavioral, and social impairments, as well as neurological abnormalities. Neuronal hyperexcitability is one of the hallmarks of neurological deficits in FXS, yet the mechanisms underlying this critical dysfunction are poorly understood (Contractor et al., 2015).

Channelopathies (i.e., abnormalities in the function and/or expression of ion channels) are recognized as critical components of excitability defects in FXS. A number of voltage-gated ion

Correspondence should be addressed to Vitaly A. Klyachko at the above address. E-mail: klyachko@wustl.edu. https://doi.org/10.1523/JNEUROSCI.1593-18.2018

Copyright $@ 2019$ the authors $\quad 0270-6474 / 19 / 390028-16 \$ 15.00 / 0$ 
channels are confirmed targets of FMRP translation regulation, including Kv1s, Kv3.1, and $\mathrm{Kv} 4.2$ potassium $\left(\mathrm{K}^{+}\right)$channels; Nav1.2 and Nav1.6 $\mathrm{Na}^{+}$channels; and $\mathrm{H}$ channels (Strumbos et al., 2010; Darnell et al., 2011; Gross et al., 2011; Lee et al., 2011; Brager et al., 2012; Routh et al., 2013,2017; Zhang et al., 2014; Kalmbach et al., 2015). FMRP is also known to directly interact with and modulate activity of several voltage-gated $\mathrm{K}^{+}$and calcium $\left(\mathrm{Ca}^{2+}\right)$ channels, such as Slack $\mathrm{K}^{+}$channels (Brown et al., 2010; Zhang et al., 2012), BK (big K ${ }^{+}$) channels (Deng et al., 2013; Myrick et al., 2015; Deng and Klyachko, 2016a), Kv1.2 channels (Yang et al., 2018), and N-type calcium channels (Ferron et al., 2014), and to indirectly modulate activity of voltagegated sodium $\left(\mathrm{Na}^{+}\right)$channels via a second messenger signaling pathway (Deng and Klyachko, 2016b). While research on neuronal excitability defects in FXS has thus far focused on voltagegated ion channels, the voltage-independent $\mathrm{K}^{+}$channels also play key roles in regulating neuronal excitability by setting the resting membrane potential and by modulating action-potential (AP) initiation and afterpotential (Bean, 2007). Whether activity or expression of voltage-independent $\mathrm{K}^{+}$channels is altered by loss of FMRP and whether such activity plays a role in neuronal hyperexcitability in FXS are unknown.

In many central neurons, calcium influx during the AP activates voltage-independent but $\mathrm{Ca}^{2+}$-dependent small conductance $\mathrm{K}^{+}$(SK) channels, which control an important component of the AP known as medium afterhyperpolarization (mAHP; Adelman et al., 2012). mAHP is critical in determining the neuronal firing rate by controlling the $\mathrm{AP}$ threshold and the voltage trajectory between the APs (Bean, 2007). Inhibition of SK channels blocks mAHP and increases neuronal excitability in many types of neurons (Adelman et al., 2012).

Here, we report that a voltage-independent ion-channel dysfunction, the abnormal SK-channel activity, causes neuronal hyperexcitability in the FXS mouse model. SK current is strongly reduced in the hippocampal CA3 pyramidal cells (PCs) of Fmr1 knock-out (KO) mice, leading to decreased AP threshold and mAHP, increased firing rate, and abnormal signal transmission of CA3 PCs. These defects were not caused by altered SK-channel expression in Fmr1 KO mice, but rather by loss of the SK-channel interaction with FMRP. The present study revealed a major role of FMRP in regulating neuronal excitability via the voltageindependent SK channels, and thus suggests a new avenue to ameliorate hippocampal excitability defects in this disorder.

\section{Materials and Methods}

Animals and slice preparation. Fmr1 $\mathrm{KO}$ and wild-type (WT) control mice on FVB (Friend leukemia virus B) or C57BL/6 (see Fig. 7) background were obtained from The Jackson Laboratory. Slices were prepared as previously described (Deng and Klyachko, 2016b). In brief, both male and female 19-24-d-old mice were used. After being deeply anesthetized with $\mathrm{CO}_{2}$, mice were decapitated and their brains were dissected out in ice-cold saline containing the following (in $\mathrm{mm}$ ): $130 \mathrm{NaCl}, 24 \mathrm{NaHCO}_{3}$, $3.5 \mathrm{KCl}, 1.25 \mathrm{NaH}_{2} \mathrm{PO}_{4}, 0.5 \mathrm{CaCl}_{2}, 5.0 \mathrm{MgCl}_{2}$, and 10 glucose, $\mathrm{pH} 7.4$ (saturated with $95 \% \mathrm{O}_{2}$ and $\left.5 \% \mathrm{CO}_{2}\right)$. Horizontal brain slices $(350 \mu \mathrm{m}$ ), including the entorhinal cortices, were cut using a vibrating microtome (Leica VT1100S). Slices were initially incubated in the above solution at $35^{\circ} \mathrm{C}$ for $1 \mathrm{~h}$ for recovery and then kept at room temperature $\left(\sim 23^{\circ} \mathrm{C}\right)$ until use. All animal procedures complied with the U.S. National Institutes of Health Guide for the Care and Use of Laboratory Animals and conformed to Washington University Animal Studies Committee guidelines.

$A P$ recording and analysis. Whole-cell patch-clamp recordings using a Multiclamp 700B amplifier (Molecular Devices) in current-clamp or voltage-clamp mode were made from CA3 PCs visually identified with infrared video microscopy and differential interference contrast optics (Olympus BX51WI). Current-clamp recordings were made with bridge-balance compensation. All recordings were conducted at nearphysiological temperature $\left(33-34^{\circ} \mathrm{C}\right)$. The recording electrodes were filled with the following (in $\mathrm{mm}$ ): $130 \mathrm{~K}$-gluconate, $10 \mathrm{KCl}, 0.1 \mathrm{EGTA}, 2$ $\mathrm{MgCl}_{2}, 2 \mathrm{ATPNa}_{2}, 0.4 \mathrm{GTPNa}$, and 10 HEPES, pH 7.3. The extracellular solution contained the following (in mM): $125 \mathrm{NaCl}, 24 \mathrm{NaHCO}_{3}, 3.5$ $\mathrm{KCl}, 1.25 \mathrm{NaH}_{2} \mathrm{PO}_{4}, 2 \mathrm{CaCl}_{2}, 1 \mathrm{MgCl}_{2}$, and 10 glucose, $\mathrm{pH} 7.4$ (saturated with $95 \% \mathrm{O}_{2}$ and $5 \% \mathrm{CO}_{2}$ ). For neuronal excitability determination, cell membrane potential was set to given potentials $(-55$ to $-49 \mathrm{mV}$ with 1 $\mathrm{mV}$ step) through the amplifier's function of automatic current injection. The number of APs within $20 \mathrm{~s}$ were averaged from four to five trials for each cell. AP threshold (i.e., threshold voltage) was defined as the voltage at the voltage trace turning point corresponding to the first peak of third-order derivative of AP trace (Lu et al., 2012; Deng and Klyachko, 2016b). For spontaneous AP recording, the membrane potential was depolarized to $-51 \mathrm{mV}$ (Deng and Klyachko, 2016b; unless stated otherwise). For evoked AP recording, we used a ramp current injection ( 0.10 pA/ms; Yamada-Hanff and Bean, 2013; Deng and Klyachko, 2016b) with a hyperpolarizing onset to ensure maximal $\mathrm{Na}^{+}$-channel availability before the first AP. The AP thresholds were determined only from the first APs of ramp-evoked AP trains. The maximal rising rate is the peak the of first-order derivative of the AP trace. The rising or falling time was the interval of $10-90 \%$ amplitude. AP duration was measured at the level of AP trace crossing $-10 \mathrm{mV}$. The fast AHP was the lowest point within 5 $\mathrm{ms}$ after the end of AP falling phase. The mAHP amplitude was measured from the baseline before the AP or the AP burst. Specifically, for the $\mathrm{mAHP}$ after a single AP in the spontaneous AP trace (see Fig. $5 A-D$ ), -51 $\mathrm{mV}$ was used as the baseline to calculate $\mathrm{mAHP}$ amplitude because we set the membrane potential at $-51 \mathrm{mV}$ to record AP firing. For the $\mathrm{mAHP}$ after the AP train (see Fig. $5 E-H$ ), we set the membrane potential at -65 $\mathrm{mV}$ (around resting membrane potential), which was thus used as baseline to calculate mAHP amplitude. For mAHP after ramp-evoked APs (see Fig. 6E), the amplitude was measured from the threshold point because the membrane potential was continuously ramped-up with time and the threshold point is the most reliable point before an AP in this setting. Data were averaged over $5-8$ trials in each cell.

Determination of resting membrane potential, capacitance, and input resistance. Resting membrane potential (RMP) was measured immediately after whole-cell formation. Cell capacitance was determined by the amplifier's automatic whole-cell compensation function with slight manual adjustment to optimize the measurement if needed. Under current-clamp mode, a negative current ( $-50 \mathrm{pA}$ for $500 \mathrm{~ms}$ ) was injected every $5 \mathrm{~s}$ to assess the input resistance.

SK-current measurement. For SK-current determination, tetraethylammonium (TEA) $(1 \mathrm{mM})$ and TTX $(1 \mu \mathrm{M})$ were added in the bath solution to inhibit other $\mathrm{K}^{+}$and $\mathrm{Na}^{+}$channels. SK current was isolated by subtracting current in $300 \mathrm{~nm}$ apamin from that before apamin. For slow voltage ramp protocol $(5 \mathrm{mV} / \mathrm{s})$, neurons were depolarized from -100 to $-25 \mathrm{mV}$, and point SK current was averaged from a $20 \mathrm{~ms}$ interval (corresponding to $0.01 \mathrm{mV}$ interval; see Fig. $4 A, B$ ). SK tail current was evoked by step depolarization from -60 to $0 \mathrm{mV}$, with 10 different step durations (from 1 to $1000 \mathrm{~ms}$; see Fig. 4C, D,F). This SK current was averaged in a $10 \mathrm{~ms}$ window, $20 \mathrm{~ms}$ after step end because the initial $15 \mathrm{~ms}$ of tail current may be contaminated by capacitance current. Cell capacitance was compensated. Series resistance compensation was enabled with $80-90 \%$ correction and $16 \mu$ s lag.

Mossy fiber-CA3 PC signal transmission. To examine signal transmission from mossy fiber (MF) to CA3 PCs, we stimulated MF in the CA3 stratum lucidum by using a monopolar glass pipette. EPSCs were recorded under voltage clamp and then APs under current clamp from CA3 PCs. To exclude the effects of the long-term plasticity and feedforward/feedback inhibition on excitatory transmission, APV $(50 \mu \mathrm{M})$, gabazine ( $5 \mathrm{mM})$, and CGP55845 $(2 \mu \mathrm{M})$ were added in the bath solution. For better comparison across cells, the membrane potential was held at $-85 \mathrm{mV}$ (to avoid uncontrolled action current) in the voltage-clamp mode to record EPSCs and was set at $-60 \mathrm{mV}$ by automatic current injection in the current-clamp mode to record APs. The site of stimula- 
tion was chosen to ensure each stimulus evokes a single EPSC (no recurrent EPSCs). The stimulation intensity was carefully adjusted for each cell to ensure each stimulus evokes only a single AP and without AP failures at the basal low-frequency stimulation $(0.2 \mathrm{~Hz})$. Under these conditions (keeping the specific site and intensity of stimulation the same for both EPSC and AP recordings in the same cell), EPSCs and subsequently APs were recorded in response to 25 stimuli at $40 \mathrm{~Hz}$. The EPSC amplitude and number of APs during the stimulus train was determined.

Western blotting. CA3 regions, isolated from the brain slices, were lysed in $2 \%$ sodium dodecyl sulfonate (SDS) with protease and phosphatase inhibitors (Roche Applied Sciences) and manually homogenized. Protein concentration was determined by DC protein assay (Bio-Rad Laboratories) against bovine serum albumin standards. Fifty micrograms of total protein were run on NuPage $4-12 \%$ Bis-Tris polyacrylamide gels (Life Technologies) and transferred to nitrocellulose membranes. Membranes were blotted with antibodies directed against the following proteins: $\alpha$-tubulin (1:20,000; Abcam, catalog \#ab18251, RRID:AB_2210057), SK1 (1:500; Alomone Labs, catalog \#APC-039, RRID:AB_2039957), SK2 (1:500; Alomone Labs, catalog \#APC-028, RRID:AB_2040126), SK3 (1:500; Alomone Labs, catalog \#APC-025, RRID:AB_2040130), rabbit IgG conjugated to horseradish peroxidase (1:10,000; ThermoFisherScientific, catalog \#656120). Blots were developed with SuperSignal West Dura (ThermoFisherScientific) and imaged with a ChemiDoc MP imaging system (Bio-Rad Laboratories).

FMRP binding assay. Whole mouse brains were homogenized on ice in lysis buffer (50 mм HEPES, pH 7.4, $300 \mathrm{~mm} \mathrm{NaCl}, 1 \%$ Triton X-100, plus protease inhibitor/phosphatase inhibitor), clarified by centrifugation at $20,000 \times$ g. GST-tagged human FMRP amino acids 1-298 $\left(\right.$ FMRP $_{298}$; Novus Biologicals, catalog \#H00002332-P01) or GST tag fragments (Novus Biologicals, catalog \#NBP-30276) were then incubated with brain lysate overnight at $4^{\circ} \mathrm{C}$. Glutathione agarose (ThermoFisherScientific, catalog \#16100) was added and incubated for $2 \mathrm{~h}$ at $4^{\circ} \mathrm{C}$, followed by centrifugation at $350 \times g$ for $1 \mathrm{~min}$. Beads were washed five times with lysis buffer before elution of bound proteins with $1 \times$ SDS/PAGE loading buffer and analysis by Western blotting.

Generation of FMRP ${ }_{234}$ transgenic mice. Fmr1(1-234) bacterial artificial chromosome (BAC) DNA, harboring WT sequence (amino acids 1-234), was linearized and sent to the Emory Transgenic Core, where it was microinjected into fertilized oocytes and implanted into pseudopregnant dams. The pups born from this process were screened for insertion of the BAC transgene by PCR genotyping and then confirmed by Southern blot. The founder pups that had confirmed BAC insertion via Southern blot were then examined for FMRP protein expression using Western blot and IC3 FMRP antibody (see Fig. $7 C, D$ ). Founder pups expressing both endogenous FMRP and truncated FMRP (1-234) were then bred with Fmr1 KO mice to generate mice that express only truncated FMRP (1-234; i.e., FMRP 234 ).

Immunohistochemistry. Mice were killed and perfused with $4 \%$ paraformaldehyde at $\sim 4$ weeks of life. Their brains were dissected and then incubated in $30 \%$ sucrose overnight. Brains were cryoembedded and then cut into $10 \mu \mathrm{m}$ sections. Sections were processed for antigen retrieval with $0.8 \% \mathrm{Na}$ borohydride, placed into hot citrate buffer, and rinsed in TBS before standard immunohistochemistry protocol. FMRP was stained using 2F5-1 mouse primary antibody (Developmental Studies Hybridoma Bank) at 1:50 dilution and incubated overnight at $4^{\circ} \mathrm{C}$.

Experimental design and statistical analysis. In the present study, we used hippocampal CA3 area as a model system to study neuronal excitability defects in the FXS mouse model. To probe neuronal excitability, we examined the AP firing rate, AP threshold, and mAHP. We then examined the mechanisms of hyperexcitability in the FXS mouse model. Finally, we reintroduced the FMRP N-terminal fragments to verify the proposed mechanisms. Data were analyzed in Matlab and Origin. Data are presented as mean \pm SEM. Student's $t$ test or Kolmogorov-Smirnov test were used for statistical analysis as appropriate. Significance was set as $p<0.05$. The $n$ was number of cells tested.

\section{Results}

\section{Hyperexcitability of CA3 PCs in Fmr1 KO mice}

The hippocampus is one of the key epileptogenic brain areas and among the main brain regions with pronounced neuropathological abnormalities in FXS individuals (Greco et al., 2011). Here, we focused on hippocampal PCs in the CA3 area, a wellcharacterized model system to study neuronal excitability mechanisms and their dysfunction in FXS (Contractor et al., 2015).

We first examined the excitability of CA3 PCs in Fmr1 KO mice, the FXS mouse model. Current clamp was used to record spontaneous AP firing of these neurons at different membrane potentials (from -55 to $-49 \mathrm{mV}$, set by automatic current injection). We found that excitability of CA3 PCs was abnormally increased in the absence of FMRP, as evident by significantly larger number of APs generated by Fmr1 KO neurons at all tested membrane potentials (Fig. $1 A, B$ ). To verify this observation, we focused on the AP firing at a membrane potential of $-51 \mathrm{mV}$, at which all tested $\mathrm{KO}$ neurons and $\sim 70 \%$ of WT neurons fired APs. Abnormal excitability of Fmr1 KO neurons was evident by the right shift in the distribution of instantaneous AP firing frequency $(p<0.0001$, Kolmogorov-Smirnov test; $n=30 \mathrm{WT}, 32$ KO; Fig. $1 C, D)$ and a $\sim 50 \%$ increase in the average firing frequency $(p=0.0003$; Fig. $1 D)$. We note that all these effects were observed in the intact hippocampal circuit in the absence of any inhibitors, indicating that circuit compensation, if present, was not sufficient to overcome these cellular excitability defects.

We further examined excitability of CA3 PCs by evaluating the spontaneous AP threshold, which represents one of the key determinants of neuronal excitability (Bean, 2007). The AP threshold was significantly decreased in CA3 neurons of Fmr1 KO mice $(p<0.0001 ; n=44 \mathrm{WT}, 39 \mathrm{KO}$; Fig, $1 E)$, confirming the increased excitability of these neurons in the absence of FMRP. These defects were not due to changes in the RMP, input resistance, or cell capacitance (Fig. $1 F$ ). Also, the maximal rising rates of $\mathrm{AP}$ upstroke, $\mathrm{AP}$ rising time, and $\mathrm{AP}$ amplitude were not altered in Fmrl KO neurons (Fig. 1G), while the excessive AP duration and reduced fast AHP defects were observed (Fig. $1 G$ ), as we previously reported (Deng et al., 2013; Myrick et al., 2015). Even though the AP threshold was $\sim-42 \mathrm{mV}$, spontaneous AP firing was observed at lower membrane potentials than the actual threshold because the spontaneous network activity and/or membrane potential fluctuation can add to the membrane potential and bring it up to the threshold level.

\section{Increased CA3 neuron excitability in Fmr1 $\mathrm{KO}$ mice is a cell-autonomous defect not caused by changes in mGluR5 signaling or persistent sodium current}

Our previous studies in the entorhinal cortex indicated that abnormal mGluR5 signaling results in enhanced persistent sodium current $\left(\mathrm{I}_{\mathrm{NaP}}\right)$ in the layer-III PCs, leading to decreased AP threshold and increased excitability (Deng and Klyachko, 2016b). This defect was not a cell-autonomous phenomenon, but rather a circuit phenomenon since layer-III PCs had normal excitability in Fmr1 KO mice when isolated from the circuit activity. Surprisingly, unlike the entorhinal cortex, inhibition of all glutamatergic and GABAergic transmission in the hippocampal slices to isolate the CA3 neurons from the circuit activity failed to abolish the differences in excitability between genotypes. Specifically, CA3 PCs in Fmrl KO mice still fired significantly more APs in the presence of a mixture of AMPA, NMDA, mGluR5, GABA $A$, and $\mathrm{GABA}_{\mathrm{B}}$ receptor blockers $(p=0.0001$; Fig. $2 A, B)$.

We sought to verify this result by examining the evoked AP threshold. Measurements were performed using a ramp protocol 
A
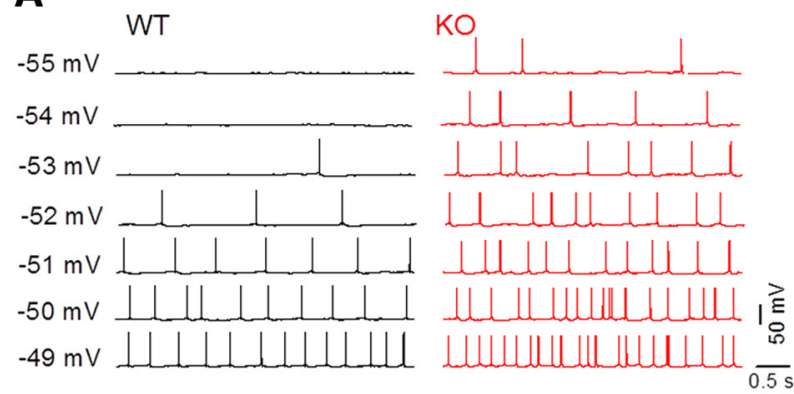

C

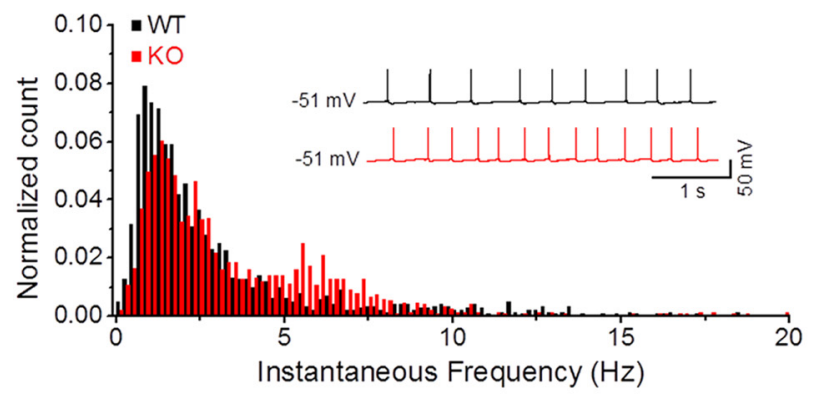

E

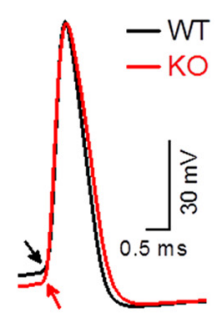

$\mathbf{F}$

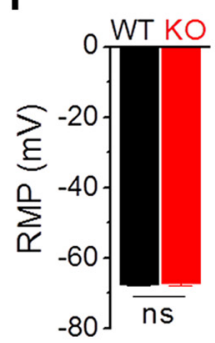

B
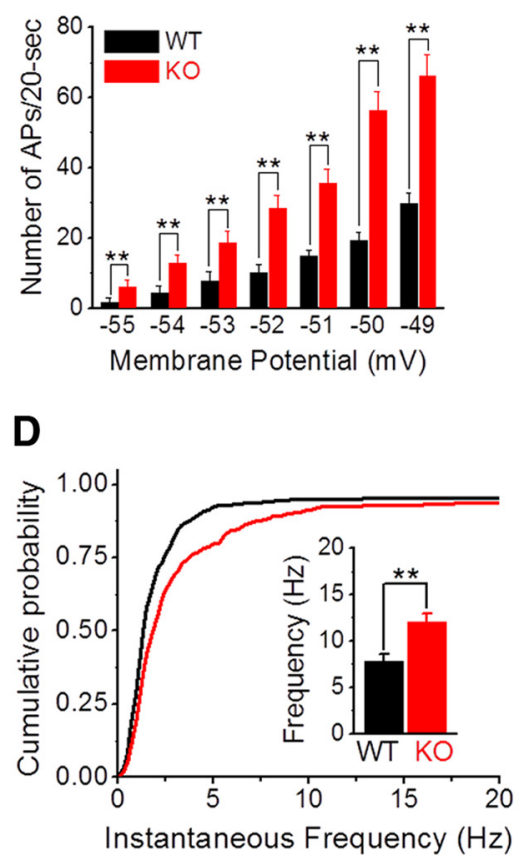

\section{G}
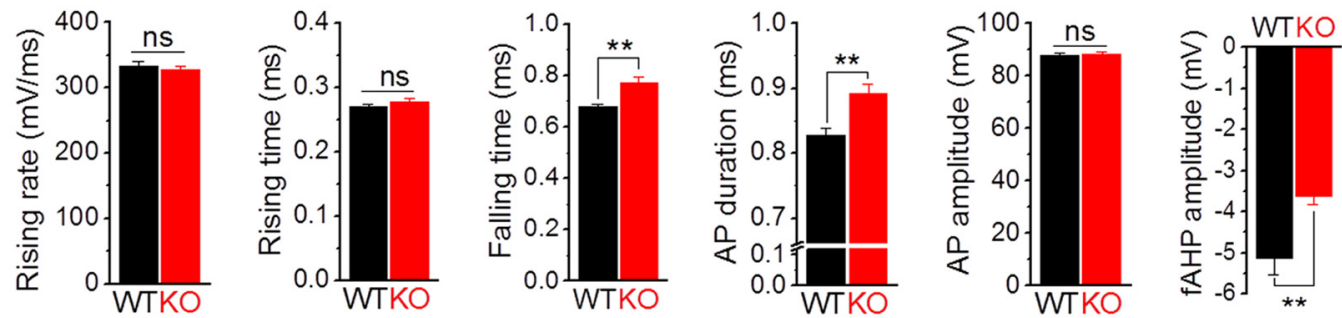

Figure 1. Increased excitability of CA3 PCs in Fmr 1 KO mice. A, Sample traces of spontaneous APs recorded at different membrane potentials in WT and Fmr 1 KO CA3 PCs. B, Analysis of recordings in $\boldsymbol{A}$ showing an increased number of APs at all tested membrane potentials in $F m r 1 \mathrm{KO}$ neurons. C, Spontaneous AP frequency distribution. APs were recorded at $-51 \mathrm{mV}$. A bin size of $0.2 \mathrm{~Hz}$ was used to calculate AP firing frequency distribution from a 20-s-long trace per cell. The number of APs within a bin was normalized to the total number of APs. Note the peak frequency of AP firing shifts rightward in Fmr1 KO neurons. D, Cumulative probability of AP frequency showed increased AP firing frequency in Fmr1 K0 neurons. Data from C (WT, $n=30 ; \mathrm{KO}, n=32, p<0.0001$, Kolmogorov-Smirnov test). Inset, Averaged AP firing frequency at $-51 \mathrm{mV}$. E, Threshold estimates for spontaneous APs. Left, Sample AP traces show a hyperpolarizing shift of threshold in $F m r 1$ K0 neurons (arrows). Right, Bar graph shows mean thresholds. F, RMP, input resistance, and membrane capacitance in CA3 PCs of WT and Fmr $1 \mathrm{KO}$ mice. Left, RMP: WT, $n=62 ; \mathrm{KO}, n=85, p=$ 0.8880; middle, input resistance: $\mathrm{WT}, n=25 ; \mathrm{KO}, n=26, p=0.88406$; right, membrane capacitance: $\mathrm{WT}, n=67 ; \mathrm{K} 0 n=65, p=0.463$. G, AP parameters (left to right): AP upstroke maximal rising rate $(p=0.653)$; AP rising time (10-90\%), $p=0.147$; AP falling time ( $90-10 \%), p<0.0001 ;$ AP duration at $-10 \mathrm{mV}$ level $(p<0.0001) ; \mathrm{AP}$ amplitude ( $p=0.628) ;$ and fast AHP (fAHP) amplitude $(p=0.0014)$. WT, $n=33 ; \mathrm{KO}, n=35 ;{ }^{* *} p<0.01$. ns, Not significant. Bar graph data are means \pm SEM.

to evoke APs, in which only the first APs were used to determine AP threshold to avoid the effect of ramp current cumulatively inactivating $\mathrm{Na}^{+}$channels on the threshold of following APs (Deng and Klyachko, 2016b). Inhibition of all glutamatergic (including mGluR5) and GABAergic transmission failed to abolish the difference in threshold between genotypes ( $p=0.0044, n=7$ WT, 7 KO; Fig. 2C-F). Moreover, unlike the entorhinal cortex, inhibition of $\mathrm{I}_{\mathrm{NaP}}$ with riluzole $(10 \mu \mathrm{M})$ also failed to abolish the differences in excitability of CA3 PCs between genotypes both in terms of the number of APs firing ( $p=0.015, n=6 \mathrm{WT}, 6$ KO; Fig. $2 B)$ and the threshold $(p=0.039$; Fig. $2 G)$. These results indicate that hyperexcitability of PCs in the hippocampus and in the entorhinal cortex layer III are mechanistically distinct phenomena. In contrast to the non-cell-autonomous 
A

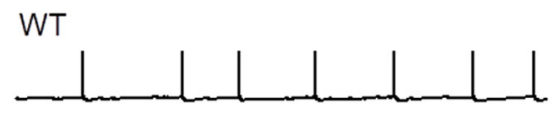

WT +5 blockers

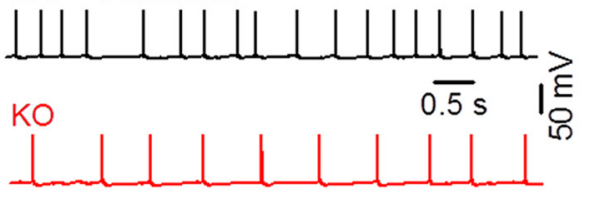

$\mathrm{KO}+5$ blockers

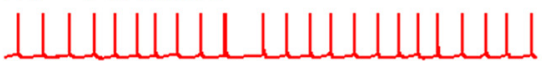

B

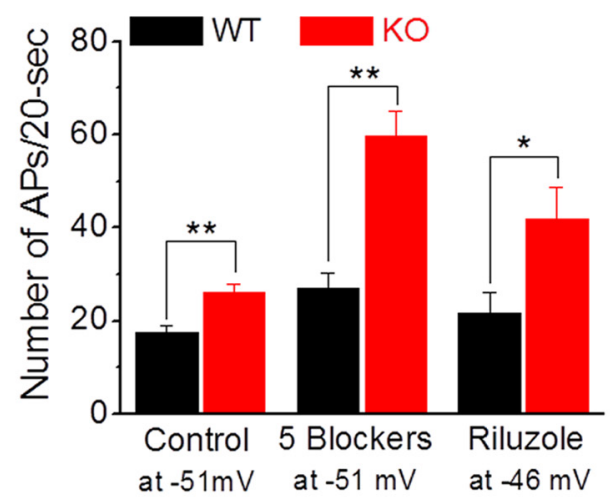

C

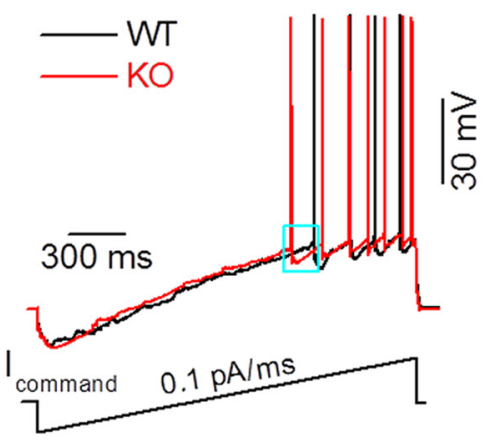

$\mathbf{F}$

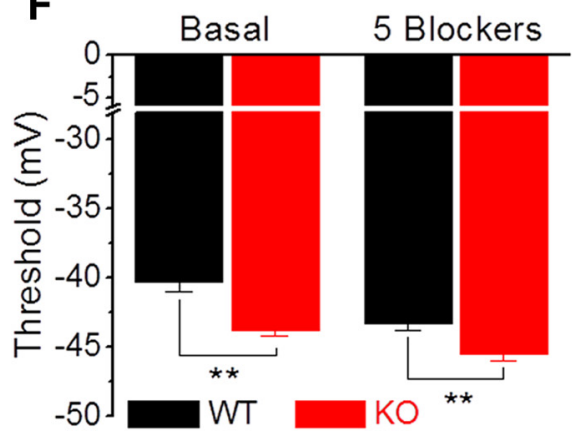

D

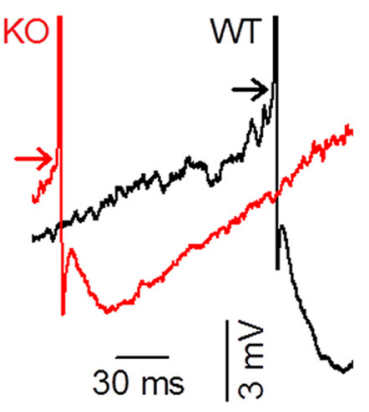

E

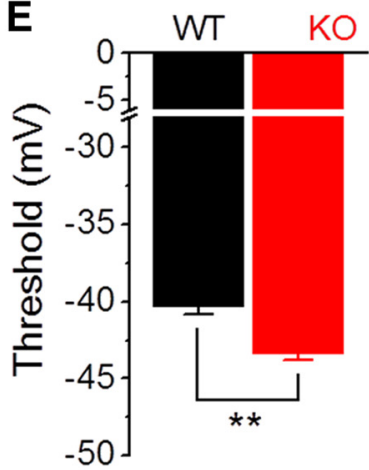

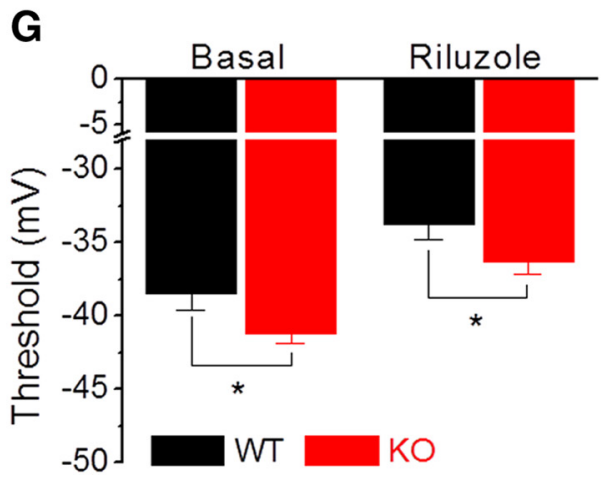

Figure 2. Increased CA3 neuron excitability in Fmr $1 \mathrm{KO}$ mice is a cell-autonomous defect, but not caused by changes in mGluR5 signaling or I ${ }_{\text {NaP. }}$ A, Spontaneous AP traces recorded with or without five blockers: DNQX, APV, MPEP, gabazine, and CGP55845. B, Number of APs in control, with five blockers, or riluzole. Note that APs were recorded at $-46 \mathrm{mV}$ in the presence of riluzole, because riluzole markedly increased threshold and no AP firing was detected at $-51 \mathrm{mV}$. C, Determination of AP threshold by a ramp current injection (lower trace, ramp rate $0.1 \mathrm{pA} / \mathrm{ms}$ ). 0 nly the first AP was used to estimate threshold (boxed area). D, Enlargement of box in C. Arrows denote the threshold in both genotypes. $\boldsymbol{E}$, Analysis of data in $\boldsymbol{C}$ showing a decreased AP voltage threshold in Fmr 1 KO neurons. $\boldsymbol{F}, A$ P threshold with and without the five blockers. $\mathbf{G}$, Same as in $\boldsymbol{F}$, but for riluzole. ${ }^{*} p<0.05,{ }^{* *} p<0.01$. Data are means \pm SEM.

mGluR5/ $\mathrm{I}_{\mathrm{NaP}}$-dependent excitability defects observed in the entorhinal cortex, the abnormal excitability of hippocampal CA3 PCs is independent of both circuit activity and changes in mGluR5 signaling or $\mathrm{I}_{\mathrm{NaP}}$.

\section{SK-channel defects decrease AP threshold in CA3 PCs of Fmr1 KO mice}

What is the mechanism of neuronal hyperexcitability in the CA3? Hyperexcitability can often be attributed to defects in expression or functional regulation of ion channels. We focused on the ion channels that are both active at subthreshold membrane potentials and known to regulate neuronal excitability. These are the Kv1, BK, H, M, and SK channels (Bean, 2007). Many of these channels are reported to be dysfunctional in FXS (Brager and Johnston, 2014; Contractor et al., 2015). For example, the somatic Kv1-mediated current is downregulated, resulting in increased PC excitability in the prefrontal cortex in Fmr1 KO mice (Kalmbach et al., 2015). Thus, we first examined whether increased excitability of CA3 PCs is caused by Kv1 channels. Kv1 blocker dendrotoxin (100 nM) decreased the thresholds both in WT and Fmr1 KO CA3 neurons, but it failed to abolish the difference in threshold between genotypes (Fig. $3 A$ ). We further found that the specific BK-channel blocker iberiotoxin (100 nM), H-channel blocker ZD7288 $(10 \mu \mathrm{M})$, and M-channel blocker XE991 $(10 \mu \mathrm{M})$ all failed to abolish the difference in AP threshold between genotypes (Fig. 3B-D). 
A

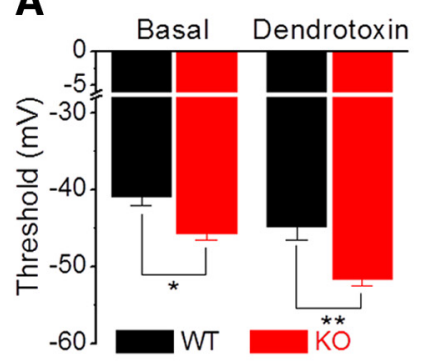

D

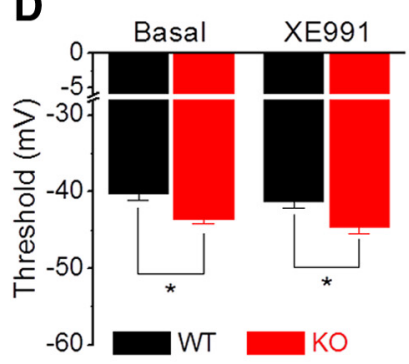

B

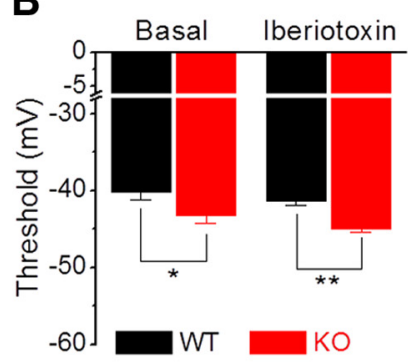

E

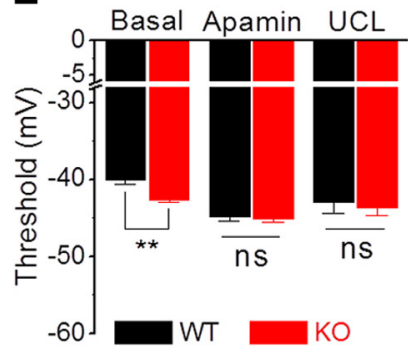

C

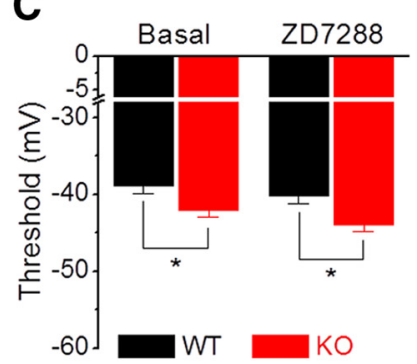

F

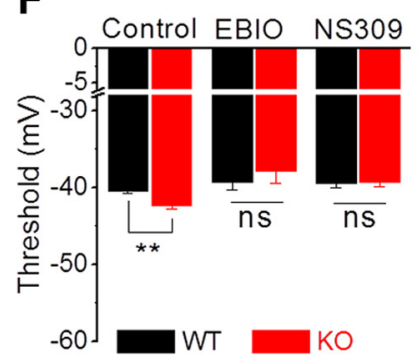

G

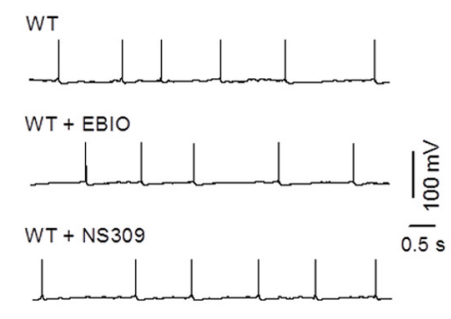

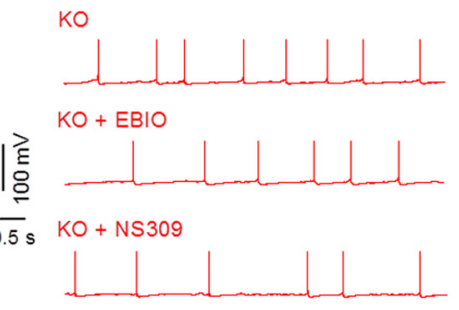

H

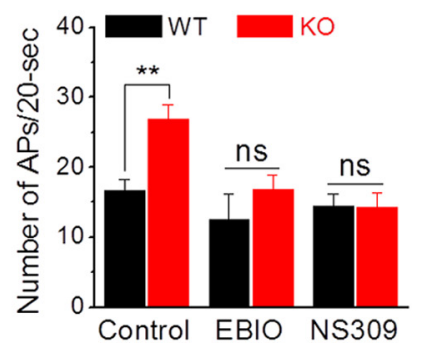

Figure 3. SK-channel defects decrease AP threshold in CA3 PCs of $F m r 1 \mathrm{~K} 0$ mice. $A$, Effect of Kv1 inhibitor dendrotoxin on AP threshold. $B$, Same as in $A$, but for the BK-channel blocker iberiotoxin. C, Same as in A, but for the H-channel blocker ZD7288. D, Same as in A, but for the M-channel blocker XE991. E, SK-channel blocker apamin or UCL1684 abolished the difference in threshold between genotypes. F, SK-channel opener 1-EBI0 or NS309 abolished the difference in threshold between genotypes. G, Sample AP traces recorded with or without intracellular administration of 1-EBI0 or NS309. $\boldsymbol{H}, 1-\mathrm{EBI} 0$ or NS309 abolished the difference in AP firing between genotypes. ${ }^{*} p<0.05,{ }^{* *} p<0.01$. ns, Not significant. Data are means \pm SEM.

In contrast, two different SK-channel blockers, apamin (300 nM) and UCL1684 (100 nM), not only decreased the AP threshold in CA3 PCs of both WT and $\mathrm{KO}$ mice, the blockers also, and more importantly, abolished the difference in threshold between genotypes (apamin: $p=0.85, n=6 \mathrm{WT}, 6 \mathrm{KO}$; UCL1684: $p=0.57$, $n=6 \mathrm{WT}, 5 \mathrm{KO}$; Fig. $3 E$ ). To verify this observation, we used two different SK-channel openers, 1-EBIO $(200 \mu \mathrm{M})$ and NS309 $(3 \mu \mathrm{M})$, to increase SK-channel activity. We included these openers in the recording pipettes to avoid circuit effects. Both 1-EBIO and NS309 abolished the difference in AP threshold between genotypes (1EBIO: $p=0.39, n=9 \mathrm{WT}, 5 \mathrm{KO}$; NS309: $p=0.91 ; n=7 \mathrm{WT}, 6 \mathrm{KO}$; Fig. $3 F$ ), as well as the differences in the number of APs fired (1EBIO: $p=0.39, N=7 \mathrm{WT}, 5 \mathrm{KO}$; NS309: $p=0.91, N=6 \mathrm{WT}, 5 \mathrm{KO}$; Fig. $3 G, H)$. These results suggest that the SK-channel deficits cause hyperexcitability of CA3 PCs in Fmr1 KO mice.

\section{SK-channel calcium sensitivity is decreased in CA3 PCs of Fmr1 KO mice}

First, we verified that SK currents are indeed reduced by loss of FMRP in CA3 PCs. SK channels do not desensitize and their gating solely depends on intracellular $\mathrm{Ca}^{2+}$ (Hirschberg et al., 1998; Xia et al., 1998). We thus used a slow voltage $\operatorname{ramp}(5 \mathrm{mV} / \mathrm{s})$ from -100 to $-25 \mathrm{mV}$ to evoke calcium influx and activate SK channels (Li and Bennett, 2007; Zhang and Huang, 2017). As expected from the above results, the apamin-sensitive (i.e., SK) current was significantly smaller in Fmr1 KO than in WT neurons $(p=0.0098, n=7$ WT, 7 KO; Fig. $4 A, B)$.

To confirm this observation, we used a complimentary, standard voltage-step protocol to measure SK current. Neurons were depolarized from -60 to $0 \mathrm{mV}$ with different step durations (from 1 to $1000 \mathrm{~ms}$ ) to evoke $\mathrm{Ca}^{2+}$ influx. After the end of each step, the tail SK current was isolated by apamin application. As in the experiments above, we observed that the SK current was significantly smaller in Fmr1 KO than in WT neurons (1000 ms step: $p=0.0028$, $n=8 \mathrm{WT}, 10 \mathrm{KO}$; Fig. $4 C, D)$. Because SK-channel activation depends on the intracellular $\mathrm{Ca}^{2+}$ and the step durations reflect amounts of $\mathrm{Ca}^{2+}$ influx, we then used step duration to construct an SK-channel activation curve. As expected, in Fmr1 KO neurons the SK-channel activation curve was right-shifted, and a longer step duration was required for SK-channel half maximum activation ( $p=$ $0.03, n=8 \mathrm{WT}, 10 \mathrm{KO}$; Fig. $4 D$, bottom, inset).

The observed reduction of SK current in Fmr1 KO mice may be attributed to a reduced cytosolic $\mathrm{Ca}^{2+}$ elevation upon depolarization or reduced $\mathrm{Ca}^{2+}$ sensitivity of the SK channels themselves. To sort out these possibilities, we sought to determine the primary source of $\mathrm{Ca}^{2+}$ that activates SK channels in CA3 neu- 
A

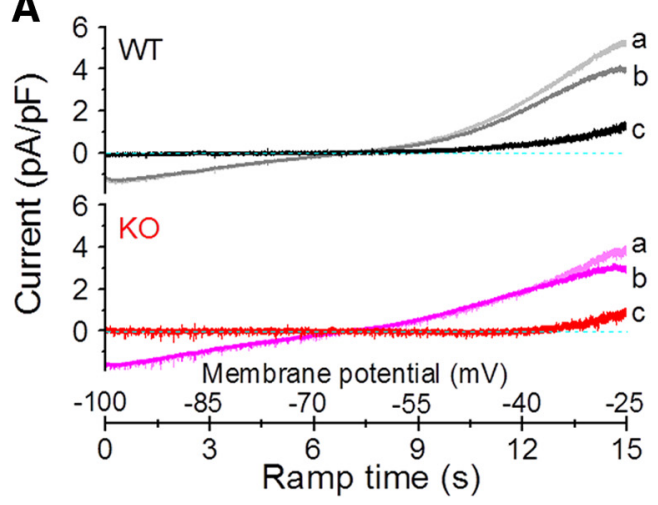

C
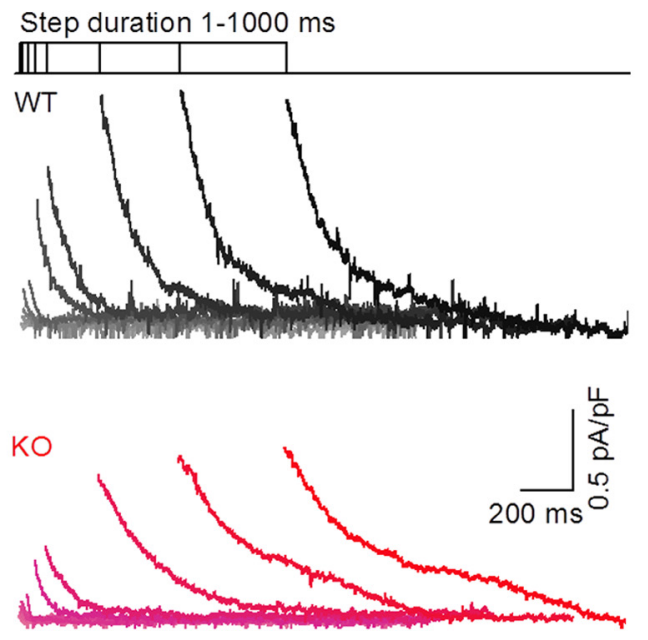

$\mathbf{E}$

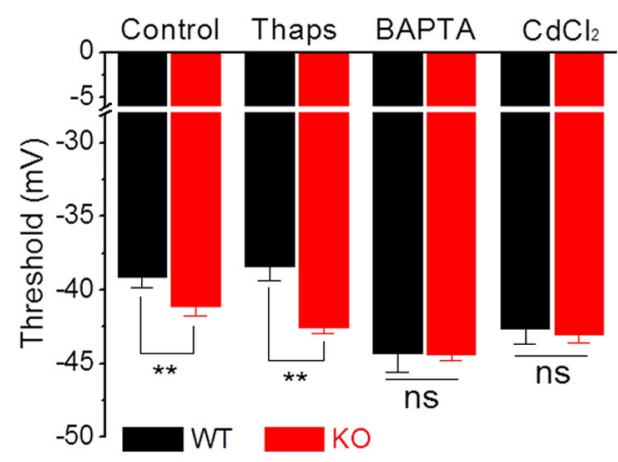

B

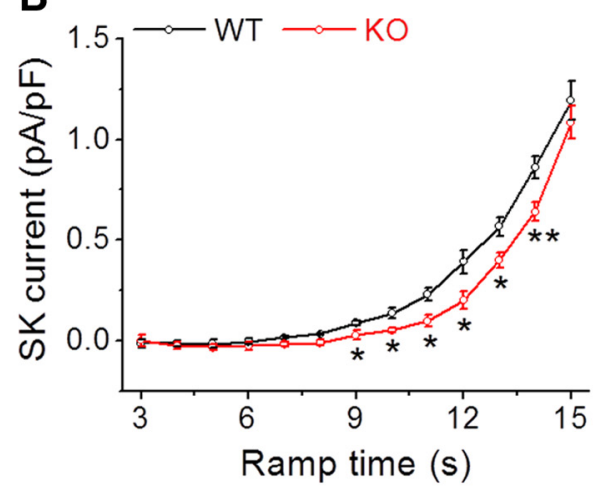

D
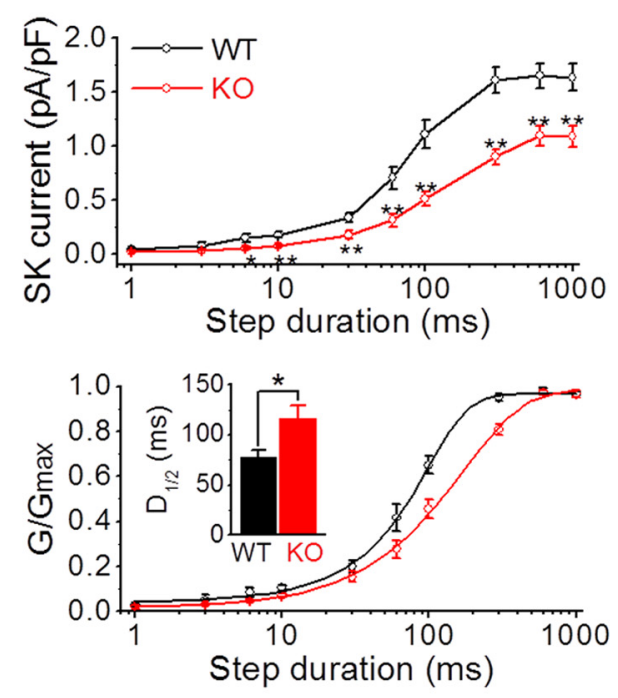

$\mathbf{F}$
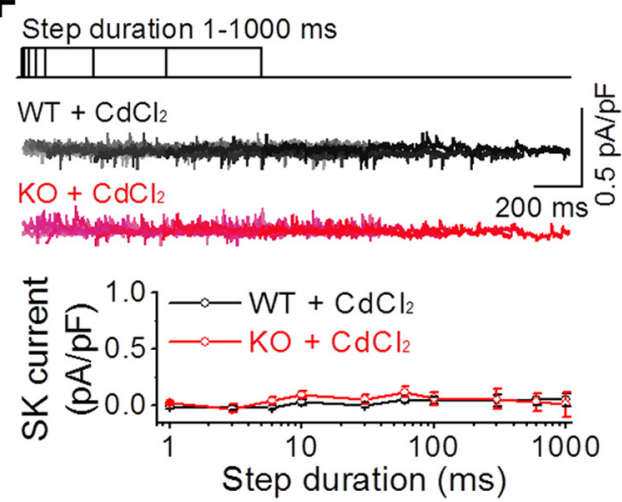

Figure 4. Decreased SK current in CA3 PCS of Fmr1 KO mice. A, Sample trace of SK current evoked by a depolarizing voltage ramp protocol (5 mV/s). a, Before apamin; $b$, during apamin; $c$, apamin-sensitive current. $B$, SK current evoked by ramp protocol. C, Sample trace of SK current evoked by voltage steps (depolarized from -60 to $0 \mathrm{mV} ; 10$ step durations; $\Delta t=1,3,6,10,30,60$, 100, 300, 600, 1000 ms). D, Top, SK currents from ( plotted as a function of step duration. Bottom, SK-channel activation curve in Fmr 1 KO neurons shifts rightward (fitted by sigmoid function). The half maximum activation step duration ( $\mathrm{D}_{1 / 2}$ ) was larger in $\mathrm{KO}$ neurons (inset). $E$, AP threshold in the presence of thapsigargin (Thaps), BAPTA, or CdCl in WT and Fmr 1 KO CA3 PCs. F, Same as in $\boldsymbol{C}$ and $\boldsymbol{D}$ (top), but in the presence of $\mathrm{CdCl}_{2} \cdot{ }^{*} p<0.05,{ }^{* *} p<0.01$. Data are means $\pm \mathrm{SEM}$.

rons. The SK-current activation and the differences in SK current between genotypes are observed during and immediately after depolarization steps as brief as $6 \mathrm{~ms}$, which suggests that the predominant source of $\mathrm{Ca}^{2+}$ for SK-channel activation in our measurements is from voltage-gated calcium channels (VGCCs) because the time course of other $\mathrm{Ca}^{2+}$ sources (such as calcium release from internal stores) is much slower. To support this notion, we examined the contribution of internal $\mathrm{Ca}^{2+}$ stores to excitability defects in CA3 PCs of Fmr1 KO mice. Application of thapsigargin $(10 \mu \mathrm{M})$, which depletes internal $\mathrm{Ca}^{2+}$ stores, failed to abolish the difference in AP threshold between genotypes (WT, $-38.44 \pm 0.91 \mathrm{mV}, n=5 ; \mathrm{KO},-42.52 \pm 0.41 \mathrm{mV}, n=6$; $p=0.00182$; Fig. $4 E$ ), suggesting that internal $\mathrm{Ca}^{2+}$ stores are not a major cause of this SK-channel-dependent hyperexcitability defect and thus are not the reason for reduced SK-channel currents in CA3 PCs of Fmr1 KO mice. We further argued that if 
VGCCs are indeed the primary source of calcium for SK-channel activation, chelation of $\mathrm{Ca}^{2+}$ with BAPTA should abolish the difference in AP threshold between WT and KO neurons. Indeed, we found that pretreatment and continuous perfusion of slices with BAPTA-AM $(10 \mu \mathrm{M})$ abolished the difference in AP threshold between genotypes (WT, $-44.31 \pm 1.27 \mathrm{mV}, n=13$; KO, $-44.42 \pm 0.40 \mathrm{mV}, n=15 ; p=0.933$; Fig. $4 E)$. Moreover, low concentration of cadmium $\left(\mathrm{CdCl}_{2}, 100 \mu \mathrm{M}\right)$, which blocks calcium influx through the VGCCs, also abolished the difference in AP threshold between genotypes (WT, $-42.61 \pm 1.09 \mathrm{mV}, n=8$; $\mathrm{KO},-43.02 \pm 0.56 \mathrm{mV}, n=7, p=0.756$; Fig. $4 E$ ) and completely inhibited the SK current (Fig. $4 F$ ). These results indicate that $\mathrm{Ca}^{2+}$ influx through VGCCs is the primary $\mathrm{Ca}^{2+}$ source that activates SK channels in CA3 PCs.

Importantly, our previous studies showed that the $\mathrm{Ca}^{2+}$ influx through the VGCCs was increased, rather than decreased, in the absence of FMRP due to prolonged AP duration in CA3 PCs of Fmr1 KO mice, and the VGCCs themselves are unaffected (Deng et al., 2011, 2013). Such increased $\mathrm{Ca}^{2+}$ influx through VGCCs cannot explain the reduced SK current in KO neurons. Therefore, neither VGCCs nor internal stores are the major causes of reduced SK current in the CA3 PCs. Thus, an alternative explanation for the abnormal SK current is a reduced SK-channel $\mathrm{Ca}^{2+}$ sensitivity in Fmr1 KO neurons. Indeed, our observations that SK activation curve was right-shifted and the half maximum activation step time (i.e., $\mathrm{Ca}^{2+}$ influx time) was significantly increased in Fmr1 KO neurons support the notion of a reduced SK-channel calcium sensitivity in Fmr1 KO mice (see Fig. 6).

\section{Abnormal SK currents decrease mAHP in CA3 PCs of Fmr1 KO mice}

In CA3 PCs, APs are followed by a pronounced mAHP, which is mediated in large part by SK channels (Bean, 2007). Thus, to confirm and extend the above results on the role of SK channels in excitability defects in the FXS mouse model, we examined whether mAHP is altered in CA3 Fmr1 KO neurons.

We first examined the mAHP after single APs by analyzing the spontaneous APs recorded at $-51 \mathrm{mV}$. We found that the $\mathrm{mAHP}$ amplitude was markedly decreased in CA3 Fmr1 KO neurons (Fig. 5A,B). More importantly, the SK-channel blockers apamin $(300 \mathrm{nM})$ and UCL1684 (100 nM) abolished the difference in mAHP amplitude between genotypes (control: $p<0.0001, n=$ $39 \mathrm{WT}, 33 \mathrm{KO}$; apamin: $p=0.62, n=6 \mathrm{WT}, 6 \mathrm{KO}$; UCL1684: $p=$ $0.86, n=6 \mathrm{WT}, 6 \mathrm{KO}$; Fig. $5 \mathrm{~B})$. As can be expected from distinct hyperexcitability mechanisms in the CA3 and the entorhinal cortex layer-III PCs of Fmr1 KO mice, the mAHP amplitude was unaffected in the latter cell population (WT, $-8.28 \pm 0.72 \mathrm{mV}$, $n=7 ; \mathrm{KO},-8.68 \pm 0.56 \mathrm{mV}, n=7, p=0.67)$, in which hyperexcitability is caused by increased $\mathrm{I}_{\mathrm{NaP}}$ rather than SK-channel defects (Deng and Klyachko, 2016b).

Because the spontaneous AP frequency varies among cells and between genotypes, which influences $\mathrm{Ca}^{2+}$ influx and thus SKchannel activation, we sought to confirm the above results using a fixed-duration train of $25 \mathrm{APs}$ at $60 \mathrm{~Hz}$ to measure mAHP after an AP burst. In line with the results above, the amplitude of mAHP after a 25-AP burst was significantly smaller in Fmr1 KO than in WT CA3 neurons $(p=0.0098, n=6 \mathrm{WT}, 12 \mathrm{KO}$; Fig. $5 E, F)$. SK-channel blocker apamin or UCL1684 decreased the amplitude of mAHP in both WT and Fmr1 KO neurons (Fig. $5 E, F)$ and, more importantly, abolished the difference in $\mathrm{mAHP}$ between genotypes (apamin: $p=0.36, n=6 \mathrm{WT}, 6 \mathrm{KO}$; UCL1684: $p=0.60 ; n=6 \mathrm{WT}, 6 \mathrm{KO}$; Fig. $5 E, F)$.
Finally, we examined whether SK-channel openers can correct the abnormally reduced mAHP in Fmrl KO neurons. 1-EBIO $(200 \mu \mathrm{M})$ or NS309 $(3 \mu \mathrm{M})$ were included in the recording pipette and spontaneous APs or AP bursts were recorded as above. mAHP after both single APs and AP bursts were markedly increased and both SK-channel openers abolished the difference in mAHP amplitude between genotypes after single APs (1-EBIO: $p=0.54, n=7 \mathrm{WT}, 5 \mathrm{KO}$; NS309: $p=0.07, n=6 \mathrm{WT}, 7 \mathrm{KO}$; Fig. $5 C, D)$ and AP bursts (1-EBIO: $p=0.64, n=6 \mathrm{WT} ; 6 \mathrm{KO}$; NS309: $p=0.09, n=6 \mathrm{WT}$; $6 \mathrm{KO}$; Fig. $5 G, H)$.

Given that $\mathrm{mAHP}$ regulates the neuronal intrinsic excitability, these results indicate that abnormal SK-channel activity promotes hyperexcitability in Fmr1 KO CA3 neurons in part via decreasing mAHP amplitude.

\section{FMRP interacts with SK2, while SK-channel expression is unaltered in CA3 pyramidal neurons of Fmr1 KO mice}

What are the molecular mechanisms that cause decreased SK current in the absence of FMRP? This defect can be caused by functional dysregulation (i.e., reduced $\mathrm{Ca}^{2+}$ sensitivity of SK channels as suggested by our experiments above) and/or reduced SK-channel expression in Fmr1 KO neurons. However, the latter is unlikely because SK channels are not among the known targets of FMRP translation regulation (Darnell et al., 2011) and our Western blot analyses showed unaltered expression of all SKchannel isoforms (SK1, SK2, and SK3) in the CA3 of Fmr1 KO mice (Fig. 6A).

To test this notion, we made functional estimates of the contributions of the SK channels to neuronal excitability in WT and Fmr1 KO neurons by comparing the changes in AP threshold caused by SK-channel modulators. SK-channel blockers apamin and UCL1684 decreased the threshold to a much larger extent in WT (3-5 mV) than in $\mathrm{KO}$ neurons (1-2 mV; Fig. 6B), as evaluated by subtracting threshold values obtained from measurements with and without the blockers (Fig. 3E). The SK-channel openers 1-EBIO and NS309 had the opposite effect by increasing the threshold in the Fmrl KO neurons to a much larger extent than in WT neurons $(\sim 1 \mathrm{mV}$ in WT; $3-4 \mathrm{mV}$ in KO; Fig. $3 F)$. These results suggest that SK channels in Fmr1 KO neurons exhibit lower activity than in WT neurons, but activity can be boosted to WT levels by the openers. Assuming the effects of channel blockers represent the amount of normally opened channels and the effects of channel openers represent the amount of normally unopened (but potentially activated) channels, the sum of relative contributions of SK-channel blockers and openers to the AP threshold reflects the total effect of SK activity on the threshold. Based on these assumptions, the combined total effect of "already-activated" and "can-be-activated" SK channels is comparable in WT and Fmr1 KO neurons (as defined by addition of the contribution of the values above: apamin + 1-EBIO: WT, $6.04 \mathrm{mV}$; KO, $7.01 \mathrm{mV}$; or UCL1684 + NS309: WT, $4.06 \mathrm{mV}$; KO, $4.11 \mathrm{mV}$; Fig. 6B). Together with results in Figure 4, these findings suggest that the decreased SK current is caused, at least in part, by the functional dysregulation of SK channels rather than changes in channel expression.

What causes this SK-channel defect in the absence of FMRP? Previous studies found that FMRP can interact with a number of $\mathrm{K}^{+}$channels, including Slack, BK, and Kv1.2 channels (Brown et al., 2010; Deng et al., 2013; Deng and Klyachko, 2016a; Yang et al., 2018), and can regulate channel gating (Brown et al., 2010) as well as calcium sensitivity (Deng et al., 2013). Therefore, to test whether FMRP interacts with SK channels, we used our previously established in vitro binding assay (Myrick et al., 2015) and 


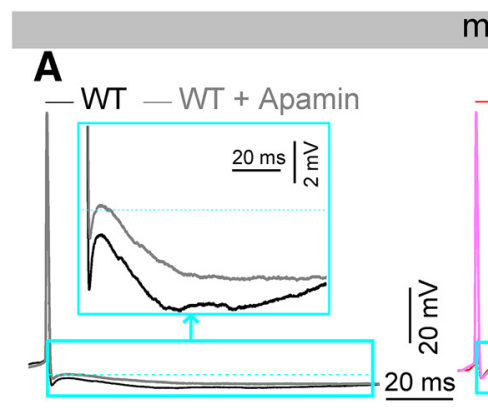

mAHP after single APs
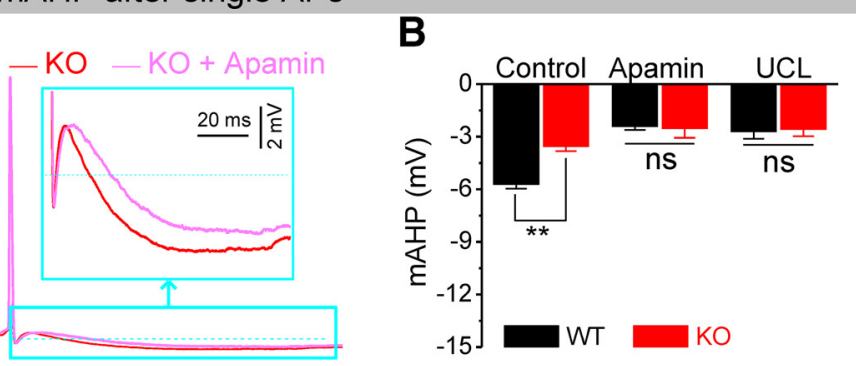

\section{C}

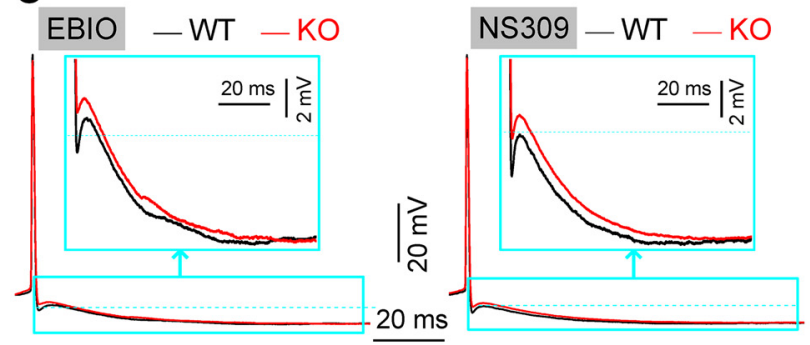

D
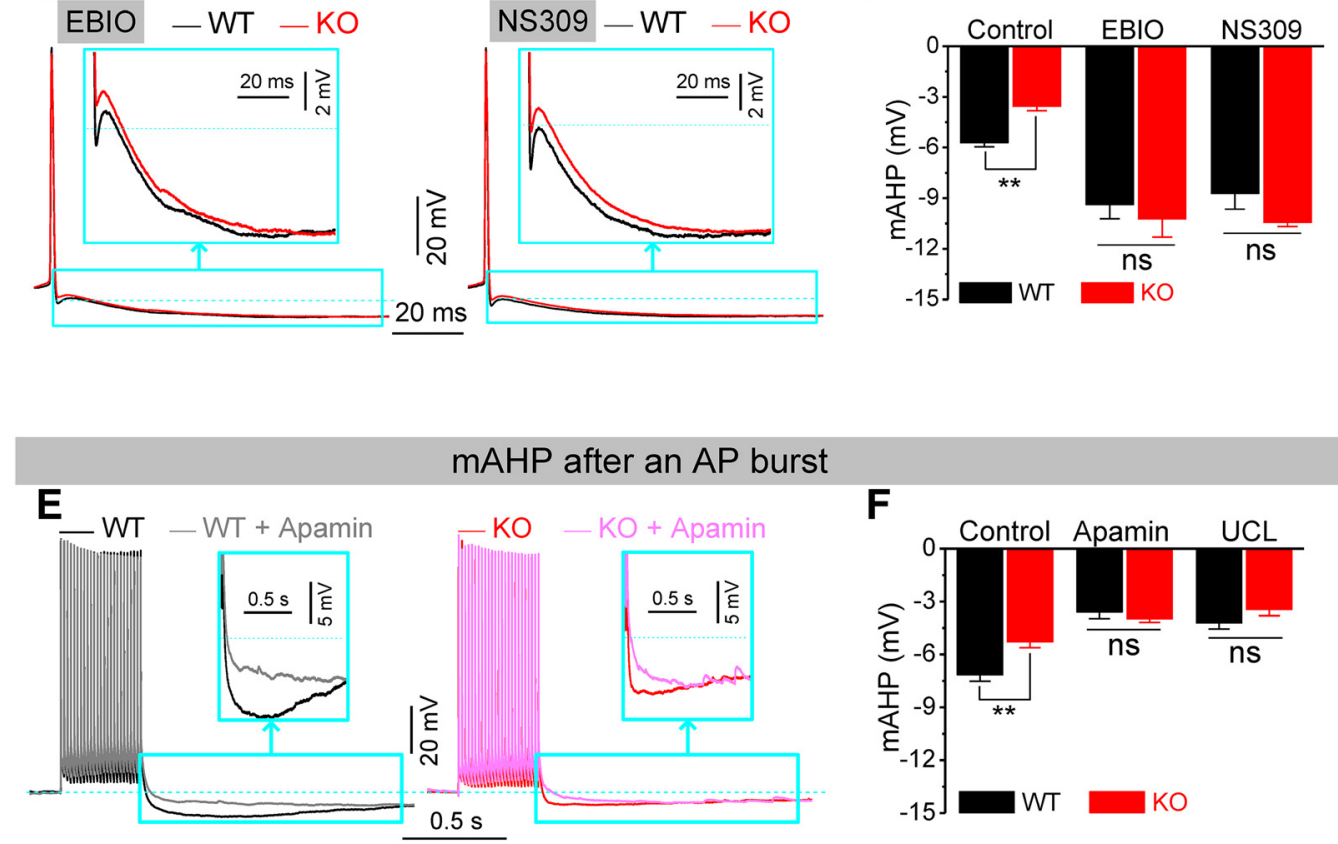

G

H
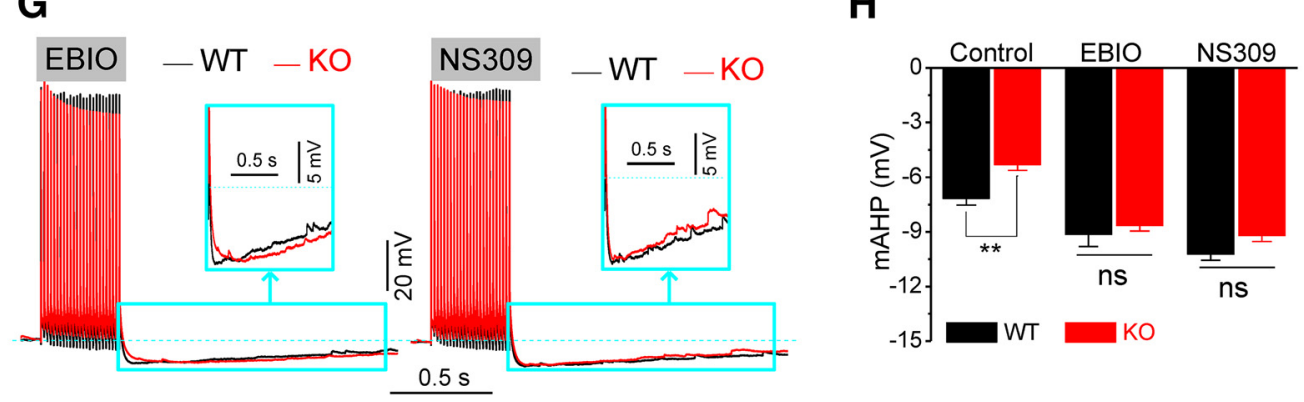

Figure 5. Abnormal SK currents cause decreased $m A H P$ in CA3 PCs of Fmr $1 \mathrm{KO}$ mice. A, Sample traces of mAHP after spontaneous APs (baseline membrane potential at $-51 \mathrm{mV}$ ). Note that SK-channel blocker apamin markedly decreased mAHP amplitude in both genotypes. B, Decreased mAHP amplitude after single APs in K0 neurons. SK-channel blockers apamin or UCL1684 markedly decreased mAHP and abolished differences between genotypes. C, Sample traces of mAHP with or without SK-channel opener 1-EBI0 or NS309. D, Either 1-EBI0 or NS309 increased mAHP amplitude both in WT and KO neurons and abolished differences between genotypes. Control bars are the same as in $\boldsymbol{B}$. $\boldsymbol{E}$, Same as in $\boldsymbol{A}$, but for mAHP after a burst of $25 \mathrm{APs}$ at $60 \mathrm{~Hz}$ (baseline membrane potential at $-65 \mathrm{mV}$ ). $\boldsymbol{F}$, Same as in $\boldsymbol{B}$, but for mAHP after AP bursts. $\boldsymbol{G}$, Same as in $\boldsymbol{C}$, but for mAHP after AP bursts. $\boldsymbol{H}$, Same as in $\boldsymbol{D}$, but for mAHP after AP bursts. Control bars are the same as in $\boldsymbol{F}$. ${ }^{*} p<0.05,{ }^{* *} p<0.01$. ns, Not significant. Data are means \pm SEM.

used GST-tagged FMRP ${ }_{298}$ or GST alone as a control to pull down SK-channel isoforms from WT brain lysates. We found that the $\mathrm{FMRP}_{298}$ fragment interacted with both isoforms of SK2 (SK2-L and SK2-S; Allen et al., 2011), but not SK1 or SK3 isoforms (Fig. $6 C)$. Notably, the FMRP ${ }_{298}$ fragment contains the protein-protein interaction NDF domain but lacks the $\mathrm{KH} 2$ domain essential for FMRP association with polyribosomes and translational regulation (Siomi et al., 1993, 1994; Feng et al., 1997; Schaeffer et al., 2001; Zang et al., 2009). Thus, these results indicate that FMRP interacts with the SK2 channel and revealed that FMRP-SKchannel interaction is mediated by the FMRP amino terminus.

\section{Genetic reintroduction of N-terminal $\mathrm{FMRP}_{234}$ fragment} rescued hyperexcitability in CA3 PCs of Fmr1 KO mice Since FMRP can interact with SK channels and SK-channel defects are not caused by changes in channel expression but represent a major underlying cause of hyperexcitability of CA3 PCs in Fmrl KO mice, we asked more broadly to what extent the hyper- 
A
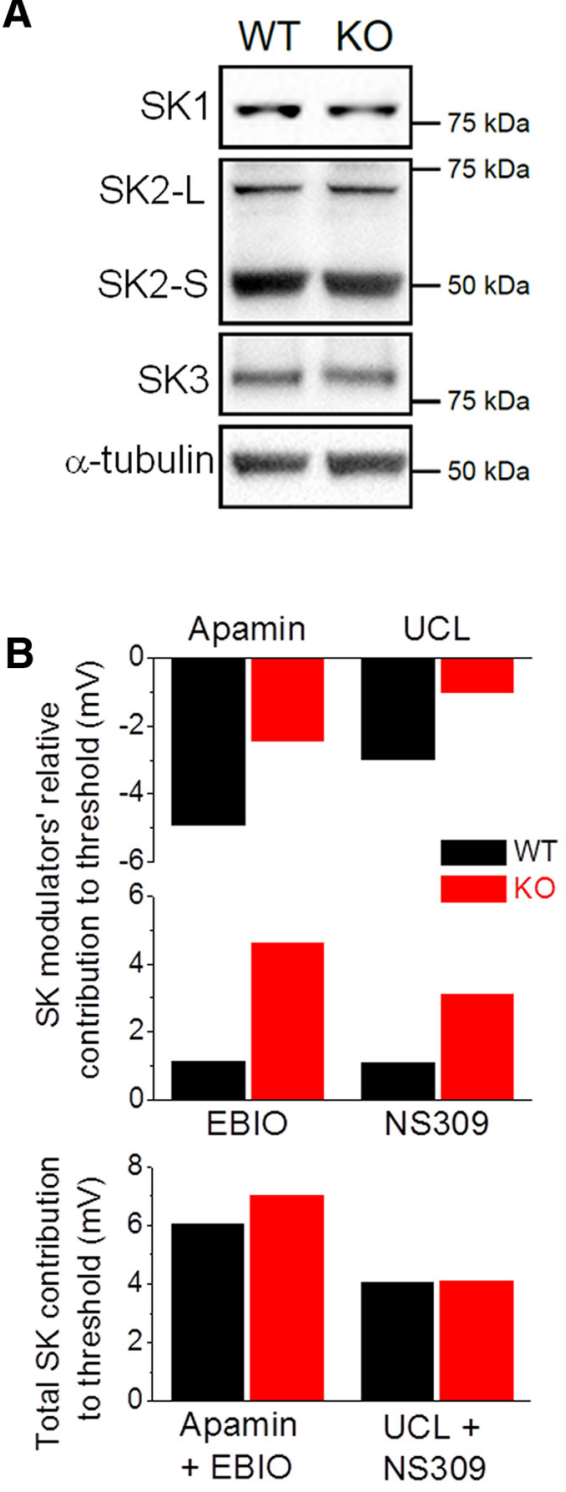

D

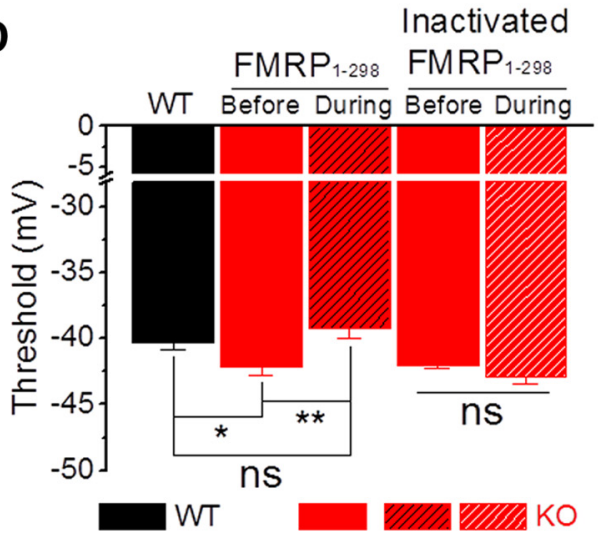

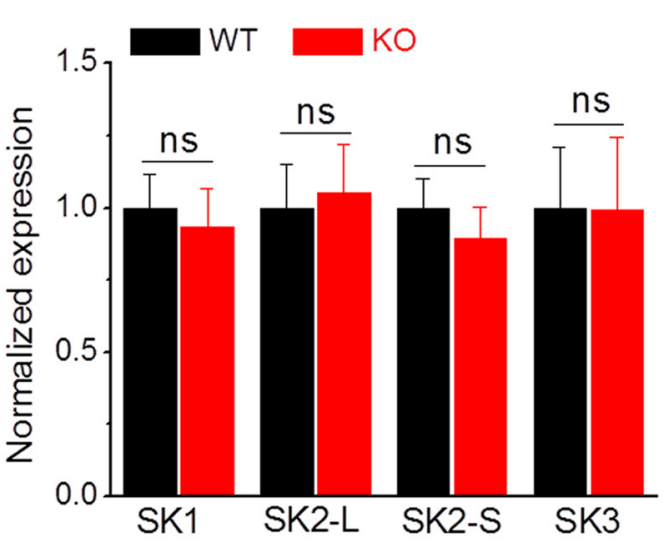

C

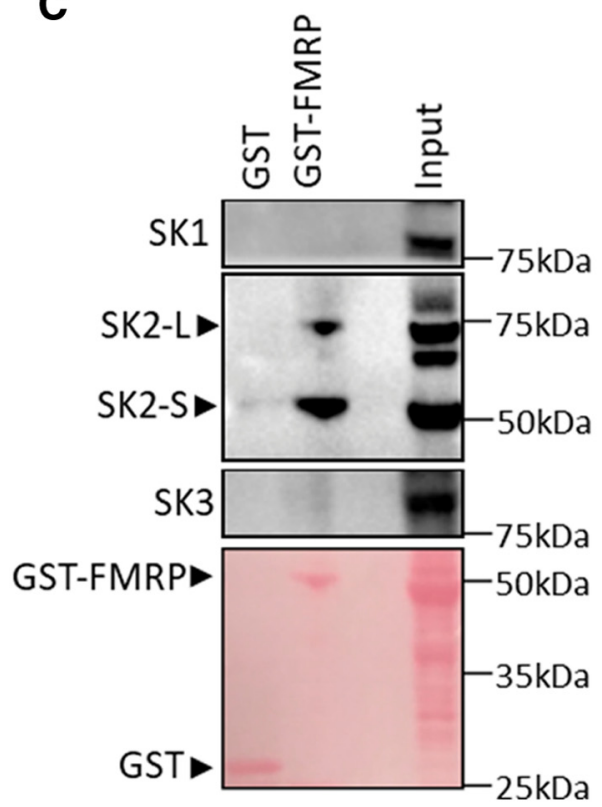

Figure 6. FMRP interacts with SK2, while expression of all SK-channel isoforms is unaltered in the CA3 of Fmr 1 KO mice. $A$, Western blot analysis from the CA3 region showed unaltered expression of all SK-channel isoforms in Fmr1 KO mice. SK-channel intensity was normalized to $\alpha$-tubulin on the same blot. Samples were then normalized to the average WT value. L and S denote long and short isoforms of SK2 (Allen et al., 2011). SK1: $N=9, p=0.711 ;$ SK2-L: $N=6, p=0.815 ;$ SK2-S: $N=6, p=0.493 ;$ SK3, $N=6, p=0.988 . B$, Estimate of total available SK-channel contribution to threshold based on Figure $3 E$, F. C, In vitro FMRP-SK-channel binding assay. Brain lysates from WT mice were incubated with GST-tagged FMRP 298 or GST tag fragments, and the levels of all SK-channel isoforms (SK1, SK2, and SK3) bound to FMRP fragments were analyzed by Western blot with the indicated antibodies. Representative Western blots from $n=4$ experiments. Ponceau staining is shown as control for an equal amount of GST-tagged FMRP ${ }_{298}$ or GST tag fragments used in this assay. $\boldsymbol{D}, \boldsymbol{E}_{\text {, Acute intracellular administration of FMRP }}$. $_{\text {normalized abnormal AP }}$ threshold $(\boldsymbol{D})$ and $\mathrm{mAHP}(\boldsymbol{E})$ in Fmr 1 KO neurons, but heat-inactivated FMRP ${ }_{298}$ failed to do this. WT data in $\boldsymbol{D}$ are from Figure $2 E$. ${ }^{*} p<0.05,{ }^{* *} p<0.01$. ns, Not significant. Data are means \pm SEM. 
excitability defects in CA3 PCs are caused by loss of translationindependent FMRP functions. We first examined whether acute administration of the $\mathrm{FMRP}_{298}$ fragment is sufficient to normalize the AP-threshold defect in Fmrl KO neurons. The FMRP ${ }_{298}$ fragment was reintroduced in CA3 PCs of Fmrl KO mice via patch pipettes using a miniaturized perfusion system (Myrick et al., 2015). Acute administration of $\mathrm{FMRP}_{298}$ indeed normalized the reduced AP threshold in KO neurons to WT level (before FMRP, $-42.16 \pm 0.61 \mathrm{mV}$; during FMRP, $-39.23 \pm 0.70 \mathrm{mV}$, $n=7, p=0.0089$; Fig. $6 D$ ). The heat-inactivated $\mathrm{FMRP}_{298}$ had no effect on AP threshold (before inactivated $\mathrm{FMRP}_{298}$, $-42.02 \pm 0.28 \mathrm{mV}$; during inactivated $\mathrm{FMRP}_{298},-42.85 \pm 0.60$ $\mathrm{mV}, n=6, p=0.235$; Fig. $6 D$ ). Since mAHP is largely mediated by SK channels in CA3 PCs, then, if FMRP ${ }_{298}$ corrects the AP threshold defects in $\mathrm{KO}$ neurons through modulation of SK channels, it should also correct the mAHP defect. Indeed, we found that $\mathrm{FMRP}_{298}$ significantly increased mAHP amplitude (before FMRP, $-8.91 \pm 0.33 \mathrm{mV}$; during FMRP, $-10.66 \pm 0.38$ $\mathrm{mV}, n=6, p=0.0041$; Fig. $6 E$ ). The heat-inactivated FMRP failed to increase the mAHP amplitude (before heat-inactivated FMRP, $-8.22 \pm 0.44 \mathrm{mV}$; during heat-inactivated FMRP, $-8.60 \pm 0.46 \mathrm{mV}, n=7, p=0.593$; Fig. $6 E$ ). Together, these findings suggest that in CA3 PCs, FMRP regulates the AP threshold via SK channels in a translation-independent manner.

We further examined the role of the translation-independent FMRP function in hyperexcitability of CA3 PCs using a genetic reintroduction of an even shorter N-terminal FMRP fragment amino acids 1-234 $\left(\mathrm{FMRP}_{234}\right)$, which, similar to $\mathrm{FMRP}_{298}$, contains the protein-protein interaction NDF domain, but lacks the $\mathrm{KH} 2$ domain essential for FMRP association with polyribosomes and translational regulation (Siomi et al., 1993, 1994; Feng et al., 1997; Schaeffer et al., 2001; Zang et al., 2009). FMRP $_{234}$ was reintroduced into Fmrl KO background mice by using BAC transgenic techniques (Fig. $7 A, B$ ). Western blot and immunostaining verified the successful reintroduction of $\mathrm{FMRP}_{234}$ (Fig. 7C,D). Because the FMRP ${ }_{234}$ mice were generated on C57BL/6 (B6) background, while we used mice on FVB background in the preceding experiments, we first confirmed that the hyperexcitability defects in CA3 PCs were present in the B6-background mice. Both the reduced AP threshold and MAHP we observed in Fmr1 KO FVB-background mice were phenocopied in Fmrl KO B6background mice (threshold: B6 WT, $-42.82 \pm 0.74 \mathrm{mV}, n=7$; B6 KO, $-44.46 \pm 0.46 \mathrm{mV}, n=11, p=0.034$; Fig. $7 E$; mAHP after single APs: B6 WT, $-8.48 \pm 0.41 \mathrm{mV}, n=7$; $\mathrm{B} 6 \mathrm{KO}$, $-7.38 \pm 0.31 \mathrm{mV}, n=11 ; p=0.029$; mAHP after AP burst: B6 WT, $-9.42 \pm 0.28 \mathrm{mV}, n=7$; $66 \mathrm{KO},-5.94 \pm 0.46 \mathrm{mV}, n=11$; $p=0.0002$; Fig. $7 F, G$ ). Genetic reintroduction of $\mathrm{FMRP}_{234}$ normalized both of these hyperexcitability phenotypes in CA3 PCs (threshold: $-42.71 \pm 0.58 \mathrm{mV}, n=13, p=0.017$ vs KO, $p=$ 0.091 vs WT; $\mathrm{mAHP}$ after single APs: $-9.31 \pm 0.68 \mathrm{mV}, n=13$, $p=0.012$ vs KO, $p=0.43$ vs WT; mAHP after AP burst: $-9.92 \pm$ $0.39 \mathrm{mV}, n=13, p<0.0001$ vs KO, $p=0.35$ vs WT; Fig. $7 E-G$ ). Most importantly, reintroduction of $\mathrm{FMRP}_{234}$ also normalized the AP firing frequency of CA3 PCs, which represents a critical readout of neuronal excitability (number of APs per $20 \mathrm{~s}$ : B6 WT, $16.4 \pm 3.9, n=7$; $\mathrm{B} 6 \mathrm{KO}, 31 \pm 3.2, n=11 ; \mathrm{FMRP}_{234}, 21.5 \pm 3.3$, $n=10$; WT vs $\mathrm{KO}, p=0.011$; WT vs $\mathrm{FMRP}_{234}, p=0.34$; Fig. $7 H, I)$. These results support the notion that translationindependent FMRP functions, including FMRP modulation of SK channels, have a major role in regulating neuronal excitability in the CA3 PCs.

\section{Implications of abnormal SK-channel activity to signal} transmission of CA3 pyramidal neurons of Fmr1 KO mice

To determine the effect of abnormal SK-channel activity on signal transmission, we examined the input-output functions of CA3 PCs in Fmr1 KO mice. We stimulated MF inputs to the CA3 in the stratum lucidum and recorded both postsynaptic EPSCs and the subsequently evoked APs from CA3 PCs. In these measurements, EPSCs reflect the input from MF, while the synaptically evoked APs represent the output of CA3 PCs in response to MF stimulation. Recordings were performed in the presence of APV $(50 \mu \mathrm{M})$, gabazine $(5 \mathrm{~mm})$, and CGP55845 $(2 \mu \mathrm{M})$ to avoid the effects of the long-term plasticity and feedforward/feedback inhibition, respectively, on excitatory transmission. The stimulation intensity was carefully adjusted for each cell to ensure that each baseline stimulus at $0.2 \mathrm{~Hz}$ evoked only a single-peak EPSC and a single AP (but there were no AP failures). Following the baseline intensity adjustment, a train of 25 stimuli at $40 \mathrm{~Hz}$ was applied and resulting EPSCs were recorded under voltage clamp followed by recording in current clamp of APs evoked by identical stimulation. We found that EPSCs were increased during the burst in both genotypes, as would be expected from a large frequency facilitation at MF synapses, but there was no significant difference in EPSC amplitude at baseline or during the trains between genotypes (actual baseline EPSC: WT, $-392 \pm 56 \mathrm{pA}$, $n=9 ; \mathrm{KO},-388 \pm 35 \mathrm{pA}, n=8, p=0.94$; normalized EPSC during the burst: $\mathrm{WT}, 2.52 \pm 0.17, \mathrm{KO}, 2.49 \pm 0.25, p=0.98$; Fig. $8 A, B)$. Despite the same MF input, the CA3 neurons in WT and Fmr1 KO mice exhibited very different patterns of output firing. Specifically, while the input train evoked mostly single APs after each stimulus during the train in WT neurons (Fig. $8 A, C$ ), the same input frequently evoked multiple APs after each stimulus in Fmr1 KO neurons (number of APs per stimulus during burst: WT, $1.08 \pm 0.035, n=9$; KO, $1.52 \pm 0.053, n=8 ; p<0.001$; Fig. $8 A, C$ ), indicating that loss of FMRP leads to hyperexcitability and abnormal signal transmission in the CA3.

If this increased excitability (exaggerated output) of CA3 PCs is caused primarily by reduced SK-channel function in Fmrl KO mice, as our results suggest, then acute enhancement of SKchannel activity should normalize output firing during bursts in Fmr1 KO neurons. We tested this prediction using intracellular perfusion of two different SK-channel openers, 1-EBIO $(200 \mu \mathrm{M})$ and NS309 $(3 \mu \mathrm{M})$. We found that both openers significantly reduced the occurrence of multiple AP firing after each stimulus during the bursts and eliminated the differences in AP firing between genotypes (number of APs per stimulus during burst: 1-EBIO: WT, $0.97 \pm 0.03, n=13$; KO, $0.93 \pm 0.04, n=12, p=$ 0.32; NS309: WT, $0.95 \pm 0.07, n=7$; KO, $1.003 \pm 0.08, n=8$, $p=0.64$; Fig. $8 D-G)$. These results confirm the critical role of SK channels in controlling AP burst firing and suggest that the reduced SK-channel activity in Fmrl KO mice may play an important role in hippocampal circuit hyperexcitability through modulation of neuronal input-output functions.

\section{Discussion}

Here, we report that a voltage-independent ion-channel dysfunction, an abnormal SK-channel activity, is a predominant cause of neuronal hyperexcitability in the hippocampus of the FXS mouse model. We found decreased SK-channel activity in CA3 PCs of Fmr1 KO mice, leading to reduced AP threshold and mAHP, elevated AP firing rate, and abnormal neuronal input-output function. All these excitability defects are normalized by the selective SK-channel openers introduced to individual CA3 PCs. Our results further suggest that abnormal SK current in Fmrl KO 
A
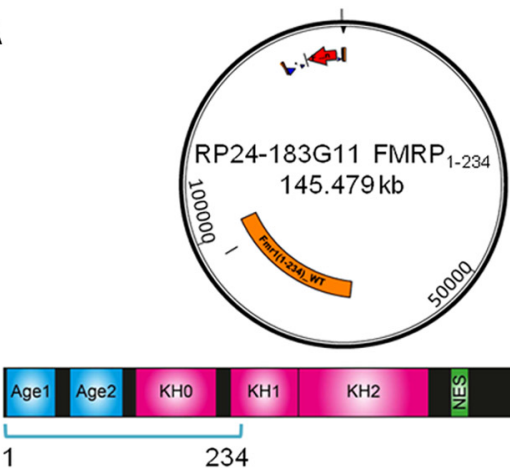

B
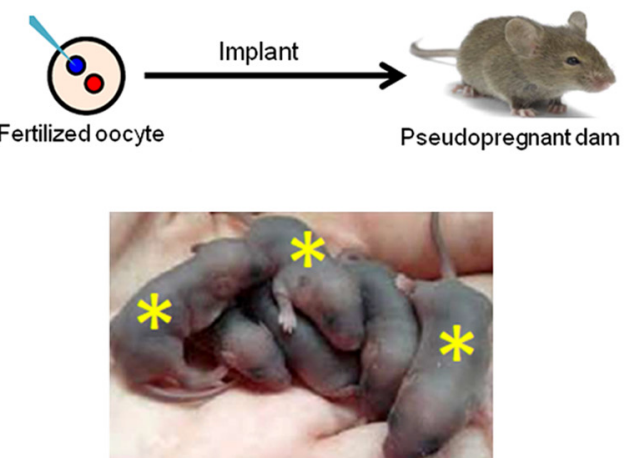

C

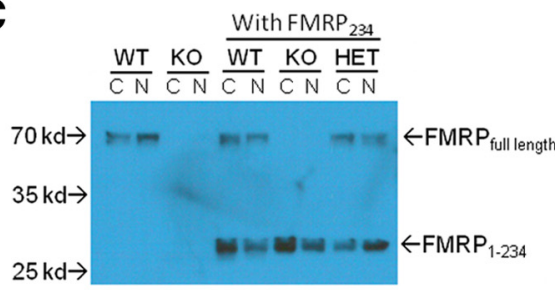

D

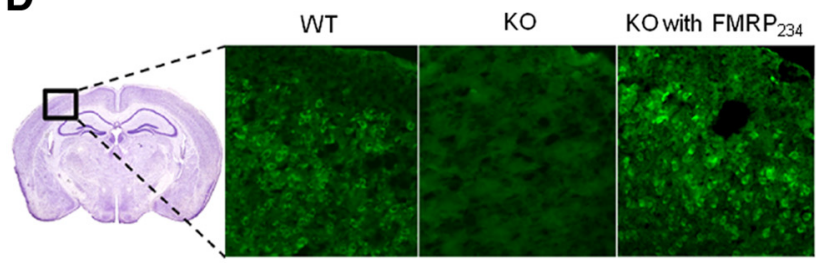

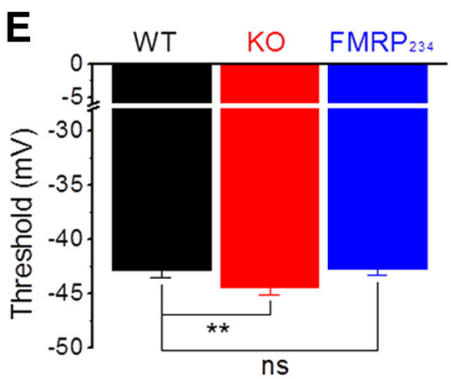

F

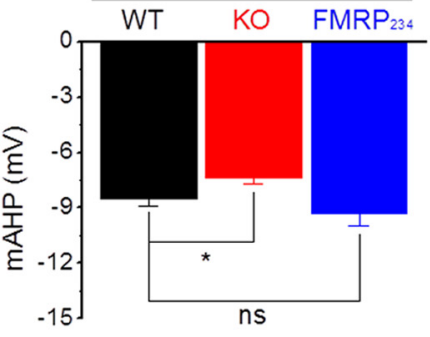

H

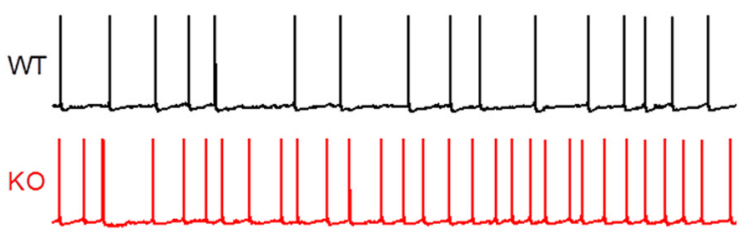

FMRP

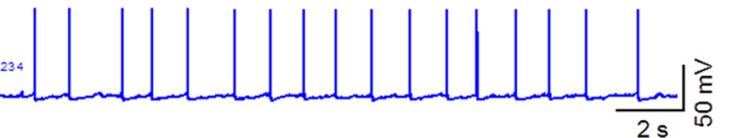

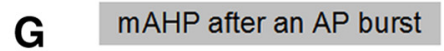

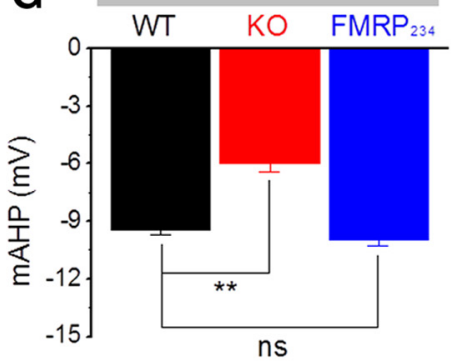

I

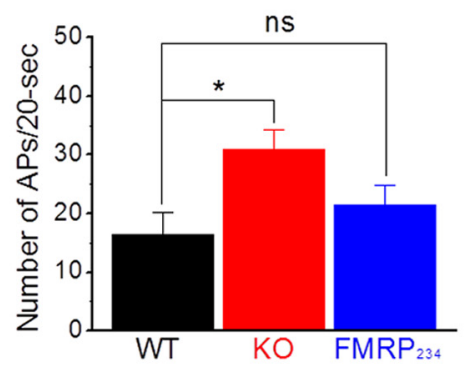

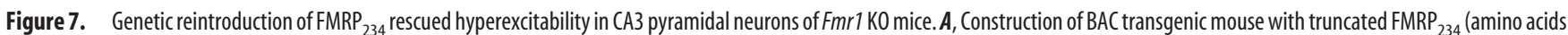
1-234). Top, BAC containing the murine Fmr1 was modified to retain only codons for amino acids 1-234, retaining all $5^{\prime}$ and $3^{\prime}$ untranslated regions. Bottom, Diagram of predicted truncated FMRP $_{234} \cdot \boldsymbol{B}, \mathrm{BAC}$ DNA was injected into fertilized oocytes and then implanted into pseudopregnant females (top). Three independent founder pups were recovered (bottom, $\left.{ }^{*}\right)$. C, Western blot of whole-brain cytoplasmic (C) or nuclear (N) lysates from WT, Fmr1 KO, and BAC transgenic mice with FMRP 234 on a background of WT, Fmr1 K0, or heterozygote (HET) showing expression of the $\mathrm{FMRP}_{234}$. D, Immunostaining of cortical slices from WT, Fmr $\mathrm{KO}$, and BAC transgenic mice on Fmr $1 \mathrm{KO}$ background showing reactivity to 2F5-1 FMRP antibody in WT and BAC transgenic (FMRP 234 ) mice. $\boldsymbol{E}$, Reintroduction of FMRP ${ }_{234}$ restored the AP threshold defects. $\boldsymbol{F}$, Reintroduction of FMRP ${ }_{234}$ restored the mAHP defects after single APs. $\boldsymbol{G}$, The same as in $\boldsymbol{F}$, but for mAHP after a burst of 25 APs at $60 \mathrm{~Hz}$ (at $-65 \mathrm{mV})$. $\boldsymbol{H}$, I, Reintroduction of FMRP 234 normalized the AP firing at $-51 \mathrm{mV}$. $\boldsymbol{H}$, Sample AP traces. I, Summarized data. ${ }^{*} p<0.05$, ${ }^{* *} p<0.01$. ns, Not significant. Data are means \pm SEM.

neurons is caused, at least in part, by loss of FMRP interaction with the SK channels (specifically the SK2 isoform), without changes in the channel expression. The major translationindependent role for FMRP as a direct regulator of neural excitability is further supported by observations that acute or genetic reintroduction of FMRP fragments lacking ability to interact with polyribosomes or regulate translation is sufficient to normalize all SK-channel-dependent excitability defects in CA3 PCs. The present study uncovers a major role of SK-channel dysfunction in hippocampal neuron hyperexcitability in the FXS mouse model. Increasing evidence links hyperexcitability in FXS with defects in ion-channel function. Previous studies focused on abnormal- 
A
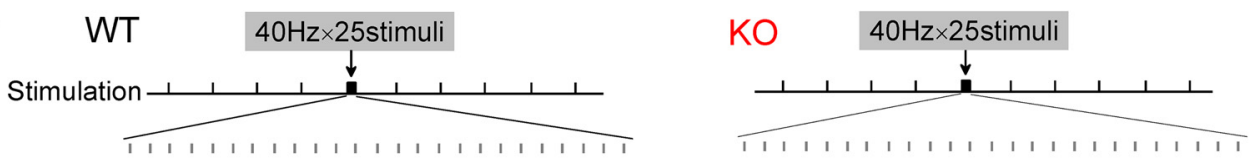

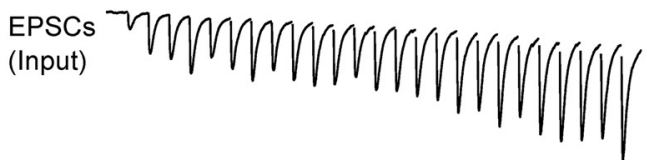
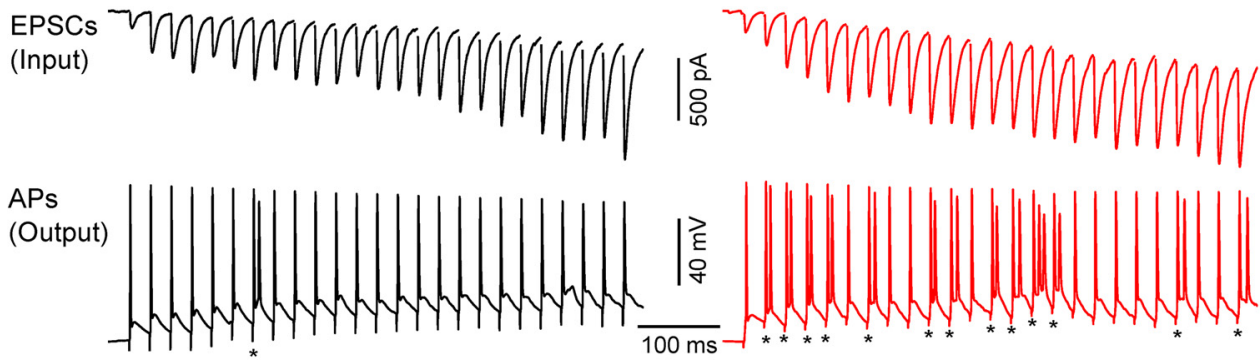

B

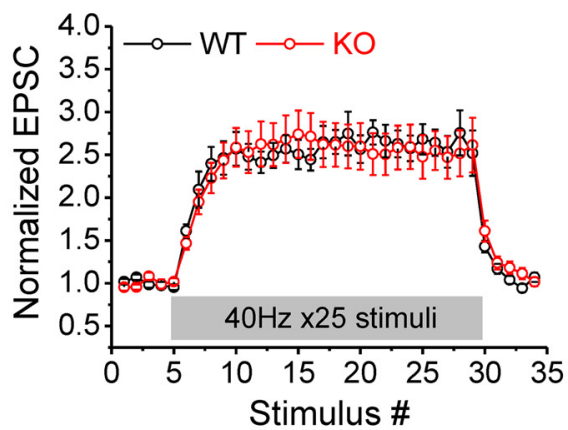

D

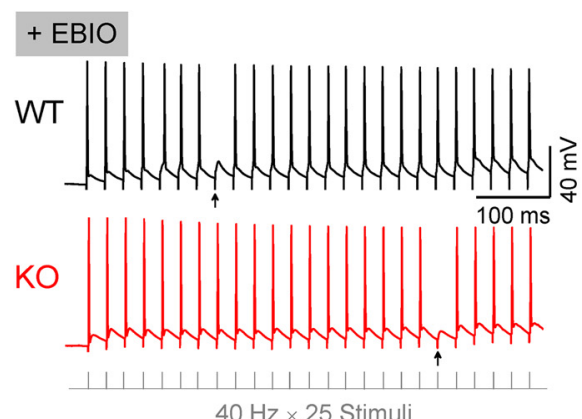

F

+ NS309

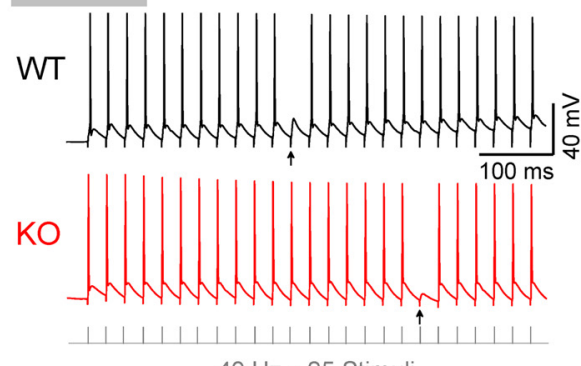

C

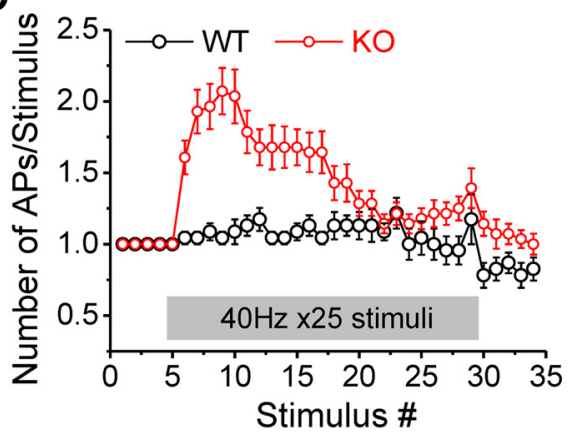

$\mathbf{E}$

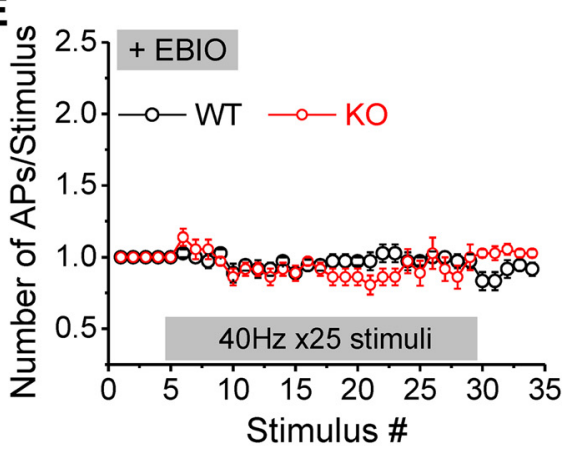

G

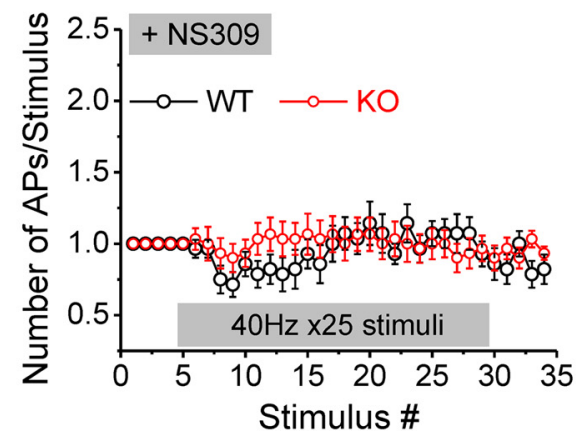

Figure 8. Abnormal SK-channel activity causes defective signal transmission in CA3 PCs of Fmr $1 \mathrm{KO}$ mice. A, Sample trace of EPSCs and APs recorded from CA3 PCs evoked by stimulating MFs. Stimulation protocol (top; $40 \mathrm{~Hz} \times 25$ stimuli); EPSCs (middle) representing input from MFs, and APs (bottom) representing CA3 PC output in response to MF input. The stimulation artifacts are shown in AP traces, but were removed from EPSC traces for clarity. Note the multiple APs that were much more frequently observed after each stimulus in Fmr 1 KO than in WT neurons $(*) . B$, EPSC amplitudes were indistinguishable in Fmr1 KO and WT neurons, both in absolute value at baseline and relative changes during the trains. $C$, AP number after each stimulus was markedly increased during the burst in Fmr $1 \mathrm{KO}$ neurons. $\boldsymbol{D}$, E, Effect of intracellular 1-EBIO on MF-CA3 PC transmission. D, Sample AP traces. Note the AP failures both in WT and Fmr 1 KO neurons ( $\uparrow$ ). E, SK-opener 1 -EBI0 rescued signal transmission of MF-CA3 PCS. $\boldsymbol{F}, \boldsymbol{G}$, Same as in $\boldsymbol{D}$ and $\boldsymbol{E}$ except for intracellular administration of NS309. ${ }^{*} p<0.05,{ }^{* *} p<0.01$. ns, Not significant. Data are means \pm SEM. 
ities in voltage-dependent ion channels leading to defects in neuronal excitability, synaptic plasticity, and information processing (Contractor et al., 2015). In the present study, in pursuit of the mechanisms of reduced AP threshold and increase excitability of CA3 PCs in Fmr1 KO mice, we focused on the ion channels that are both active at subthreshold membrane potentials and that regulate neuronal excitability: $\mathrm{I}_{\mathrm{NaP}}, \mathrm{Kv1}, \mathrm{H}, \mathrm{M}, \mathrm{BK}$, and SK channels (Bean, 2007). Among these, $\mathrm{I}_{\mathrm{NaP}}, \mathrm{Kv1}, \mathrm{H}$, and $\mathrm{M}$ channels are voltage-gated, $\mathrm{BK}$ channels are both voltage-activated and $\mathrm{Ca}^{2+}$ activated, and SK channels are solely $\mathrm{Ca}^{2+}$-activated. We found that none of the above voltage-gated channels underlie the reduced AP threshold in the CA3 PCs of Fmr1 KO mice. On the contrary, our analyses indicate that voltage-independent SKchannel dysfunction is the primary cause of neuronal excitability defects in the CA3 PCs of Fmr1 KO mice, including reduced AP threshold and $\mathrm{mAHP}$, as well as increased AP firing. These excitability defects are a cell-autonomous phenomenon, as they are observed in neurons isolated from the circuit activity and are rescued by introduction of SK-channel openers or $\mathrm{FMRP}_{298}$ into individual CA3 neurons. Thus, hippocampal neuron hyperexcitability is mechanistically distinct from the excitability defects we previously observed in the entorhinal cortex of Fmr1 KO mice, in which reduced AP threshold was dependent on circuit activity and mediated by abnormal mGluR5 signaling causing an enhanced $\mathrm{I}_{\mathrm{NaP}}$ (Deng and Klyachko, 2016b). The presence of multiple distinct hyperexcitability mechanisms in different brain regions is not surprising, as many of the voltage-dependent and voltage-independent ion channels have distinct patterns of expression and may differentially contribute to regulation of RMP, AP threshold, and neuronal excitability in a brain region-specific and cell-type-specific manner. Indeed, no changes in $\mathrm{I}_{\mathrm{NaP}}$ were observed in layer-2/3 PCs in the prefrontal cortex of Fmr1 KO mice (Routh et al., 2017). Increased excitability of these layer-2/3 neurons was instead attributed to increased transient $\mathrm{Na}^{+}$current. Yet, the unaltered $\mathrm{AP}$ rising time and maximal $\mathrm{AP}$ rising rate in our measurements in the CA3 neurons argues against a contribution from transient $\mathrm{Na}^{+}$conductance to hippocampal PC excitability. Similar brain-region-specific differences were observed for the $I_{h}$ current, which is increased in the CA1 PCs (Brager et al., 2012), but is downregulated in the somatosensory cortex layer V of Fmr1 KO mice (Zhang et al., 2014) and in the prefrontal cortex layer-V PCs (Kalmbach et al., 2015). Moreover, currents mediated by the Kv1 and Kv4 channels show distinct patterns of changes in the two subpopulations of PCs in the same cortical area of Fmr1 KO mice, and these changes are opposite from the changes in the same channels observed in the hippocampus (Kalmbach et al., 2015). These differential effects could arise from combined changes in channel expression, activity, or localization, all of which have been reported to occur as a result of FMRP loss (Contractor et al., 2015).

The decreased SK current we observed in Fmr1 KO neurons may be attributed to alterations in the SK channel itself (e.g., decreased expression and/or reduced $\mathrm{Ca}^{2+}$ sensitivity) or decreased cytosolic $\mathrm{Ca}^{2+}$ concentration (e.g., reduced $\mathrm{Ca}^{2+}$ influx). SK channels can be activated by elevation in cytosolic $\mathrm{Ca}^{2+}$ from multiple sources: $\mathrm{Ca}^{2+}$ influx via VGCCs or via receptoroperated channels (NMDA or nAch receptors), $\mathrm{Ca}^{2+}$ release from internal stores, or a combination of these processes (Adelman et al., 2012). In our setting, the SK-current activation and the differences in SK current between genotypes can be seen during and immediately after depolarization steps as brief as $6 \mathrm{~ms}$, indicating that the predominant source of $\mathrm{Ca}^{2+}$ for SK-channel activation in our measurements is from VGCCs because the time course of other $\mathrm{Ca}^{2+}$ sources is much slower. This notion is further supported by the observations that (1) low concentration of $\mathrm{CdCl}_{2}$ that blocks calcium influx through the VGCCs eliminated SK current and abolished the difference in AP threshold between genotypes; (2) chelation of $\mathrm{Ca}^{2+}$ with BAPTA abolished the difference in AP threshold between genotypes; and (3) in contrast, depletion of internal $\mathrm{Ca}^{2+}$ stores with thapsigargin failed to abolish the difference in threshold between genotypes. Our previous studies found that VGCCs are unaffected (Deng et al., 2011, 2013) and $\mathrm{Ca}^{2+}$ influx is actually increased in CA3 PCs of Fmr1 $\mathrm{KO}$ mice due to prolonged AP duration, which cannot explain the decreased SK current. Thus, one plausible explanation for the reduced SK current in KO neurons is that the channel itself changed. Specifically, our results suggest that FMRP can interact with the SK channels and that the $\mathrm{Ca}^{2+}$ sensitivity of SK channels is decreased due to FMRP loss. This is supported by the evidence of in vitro FMRP-SK2 interaction, a right shift of the SK-channel activation curve, an increase of the half maximal activation step duration (reflecting $\mathrm{Ca}^{2+}$ influx time), and unaltered SKchannel expression in Fmr1 KO neurons. It is noteworthy that the increased $\mathrm{Ca}^{2+}$ influx in Fmr1 KO neurons can act to compensate, at least in part, for the reduced $\mathrm{Ca}^{2+}$ sensitivity of the SK channels. Since we still observed a reduced SK current in Fmr1 $\mathrm{KO}$ mice, this compensation is insufficient to overcome the reduced $\mathrm{Ca}^{2+}$ sensitivity of SK channels. Similar observations were reported for BK channels in CA3 PCs of Fmr1 KO mice, in which enhanced $\mathrm{Ca}^{2+}$ influx fails to overcome the reduced $\mathrm{Ca}^{2+}$ sensitivity of BK channels, resulting in uncompensated prolongation of AP duration (Deng et al., 2013).

In addition to its well-established function in regulating local translation, FMRP has a noncanonical function in directly regulating excitability via interactions with a number of voltage-gated ion channels. The N-terminal NDF domain of FMRP contains two protein-protein interaction Tudor domains that interact with Slack $\mathrm{K}^{+}$channels and BK channels, as well as with Kv1.2 channels, to regulate their gating (Brown et al., 2010; Zhang et al., 2012; Deng et al., 2013; Deng and Klyachko, 2016a; Yang et al., 2018). Our observations suggest that SK-channel deficits in Fmr1 KO mice may also arise from loss of FMRP modulation of the channel activity, rather than changes in channel expression. Indeed, we found that FMRP can interact with the SK2 isoform; SK channels are not a known target of FMRP translational regulation and we observed that all three SK-channel isoforms have normal expression levels in the CA3 of Fmr1 KO mice. This notion is further supported by our findings that SK-channel-dependent excitability defects in the CA3 PCs are normalized by an acute reintroduction of $\mathrm{FMRP}_{298}$ or a genetic reintroduction of $\mathrm{FMRP}_{234}$ fragments lacking essential RNA binding domains $\mathrm{KH} 2$ and RGG box, as well as the ability to associate with polyribosomes (Santoro et al., 2012). Because previous studies have established that the $\mathrm{KH} 2$ domain is absolutely required to enable FMRP to regulate translation (Siomi et al., 1993, 1994; Feng et al., 1997; Schaeffer et al., 2001; Zang et al., 2009), the rescue effects of the $\mathrm{N}$-terminal FMRP ${ }_{234}$ or $\mathrm{FMRP}_{298}$ fragments on excitability in the CA3 is likely mediated by the protein-protein interaction functions of FMRP. Our results thus provide strong evidence for a major role of translation-independent FMRP function in directly regulating neural excitability in the hippocampus.

SK channels are widely expressed throughout the CNS and provide critical negative feedback control to counter hyperexcitability, while also regulating synaptic transmission, synaptic plasticity, and dendritic integration, thus influencing learning and memory (Adelman et al., 2012). Indeed, SK channels play critical 
roles in LTP induction (Stackman et al., 2002; Griffith et al., 2016) and spike timing-dependent plasticity. (Jones et al., 2017). Also, SK channels have been implicated in a number of neurological disorders, including epilepsy (Schulz et al., 2012; Lam et al., 2013; Huang et al., 2018). Given that hyperexcitability-associated phenotypes are common in FXS, our findings that dysfunction of SK channels has a profound effect on neuronal excitability and signal transmission in the hippocampus of Fmr1 KO mice suggest that these channels may play an important role in the pathophysiology of FXS. SK channels may thus represent a therapeutic target for treating hippocampal hyperexcitability defects in FXS.

\section{References}

Adelman JP, Maylie J, Sah P (2012) Small-conductance Ca2+-activated K+ channels: form and function. Annu Rev Physiol 74:245-269. CrossRef Medline

Allen D, Bond CT, Luján R, Ballesteros-Merino C, Lin MT, Wang K, Klett N, Watanabe M, Shigemoto R, Stackman RW Jr, Maylie J, Adelman JP (2011) The SK2-long isoform directs synaptic localization and function of SK2-containing channels. Nat Neurosci 14:744-749. CrossRef Medline

Bean BP (2007) The action potential in mammalian central neurons. Nat Rev Neurosci 8:451-465. CrossRef Medline

Brager DH, Johnston D (2014) Channelopathies and dendritic dysfunction in fragile X syndrome. Brain Res Bull 103:11-17. CrossRef Medline

Brager DH, Akhavan AR, Johnston D (2012) Impaired dendritic expression and plasticity of h-channels in the fmr $1(-/ y)$ mouse model of fragile $\mathrm{X}$ syndrome. Cell Rep 1:225-233. CrossRef Medline

Brown MR, Kronengold J, Gazula VR, Chen Y, Strumbos JG, Sigworth FJ, Navaratnam D, Kaczmarek LK (2010) Fragile X mental retardation protein controls gating of the sodium-activated potassium channel slack. Nat Neurosci 13:819-821. CrossRef Medline

Contractor A, Klyachko VA, Portera-Cailliau C (2015) Altered neuronal and circuit excitability in fragile $\mathrm{X}$ syndrome. Neuron 87:699-715. CrossRef Medline

Darnell JC, Van Driesche SJ, Zhang C, Hung KY, Mele A, Fraser CE, Stone EF, Chen C, Fak JJ, Chi SW, Licatalosi DD, Richter JD, Darnell RB (2011) FMRP stalls ribosomal translocation on mRNAs linked to synaptic function and autism. Cell 146:247-261. CrossRef Medline

Deng PY, Klyachko VA (2016a) Genetic upregulation of BK channel activity normalizes multiple synaptic and circuit defects in a mouse model of fragile X syndrome. J Physiol 594:83-97. CrossRef Medline

Deng PY, Klyachko VA (2016b) Increased persistent sodium current causes neuronal hyperexcitability in the entorhinal cortex of Fmrl knockout mice. Cell Rep 16:3157-3166. CrossRef Medline

Deng PY, Sojka D, Klyachko VA (2011) Abnormal presynaptic short-term plasticity and information processing in a mouse model of fragile $\mathrm{X}$ syndrome. J Neurosci 31:10971-10982. CrossRef Medline

Deng PY, Rotman Z, Blundon JA, Cho Y, Cui J, Cavalli V, Zakharenko SS, Klyachko VA (2013) FMRP regulates neurotransmitter release and synaptic information transmission by modulating action potential duration via BK channels. Neuron 77:696-711. CrossRef Medline

Feng Y, Absher D, Eberhart DE, Brown V, Malter HE, Warren ST (1997) FMRP associates with polyribosomes as an mRNP, and the I304N mutation of severe fragile X syndrome abolishes this association. Mol Cell 1:109-118. CrossRef Medline

Ferron L, Nieto-Rostro M, Cassidy JS, Dolphin AC (2014) Fragile X mental retardation protein controls synaptic vesicle exocytosis by modulating N-type calcium channel density. Nat Commun 5:3628. CrossRef Medline

Greco CM, Navarro CS, Hunsaker MR, Maezawa I, Shuler JF, Tassone F, Delany M, Au JW, Berman RF, Jin LW, Schumann C, Hagerman PJ, Hagerman RJ (2011) Neuropathologic features in the hippocampus and cerebellum of three older men with fragile X syndrome. Mol Autism 2:2. CrossRef Medline

Griffith T, Tsaneva-Atanasova K, Mellor JR (2016) Control of Ca2+ influx and calmodulin activation by SK-channels in dendritic spines. PLoS Comput Biol 12:e1004949. CrossRef Medline

Gross C, Yao X, Pong DL, Jeromin A, Bassell GJ (2011) Fragile X mental retardation protein regulates protein expression and mRNA translation of the potassium channel Kv4.2. J Neurosci 31:5693-5698. CrossRef Medline

Hirschberg B, Maylie J, Adelman JP, Marrion NV (1998) Gating of recom- binant small-conductance Ca-activated $\mathrm{K}+$ channels by calcium. J Gen Physiol 111:565-581. CrossRef Medline

Huang Y, Liu X, Wang G, Wang Y (2018) SK channels participate in the formation of after burst hyperpolarization and partly inhibit the burst strength of epileptic ictal discharges. Mol Med Rep 17:1762-1774. CrossRef Medline

Jones SL, To MS, Stuart GJ (2017) Dendritic small conductance calciumactivated potassium channels activated by action potentials suppress EPSPs and gate spike-timing dependent synaptic plasticity. Elife 6:pi:30333. CrossRef Medline

Kalmbach BE, Johnston D, Brager DH (2015) Cell-type specific channelopathies in the prefrontal cortex of the fmr1-/y mouse model of fragile $\mathrm{X}$ syndrome. eNeuro 2.pii:ENEURO.01144-15.2015. CrossRef Medline

Lam J, Coleman N, Garing AL, Wulff H (2013) The therapeutic potential of small-conductance $\mathrm{KCa} 2$ channels in neurodegenerative and psychiatric diseases. Expert Opin Ther Targets 17:1203-1220. CrossRef Medline

Lee HY, Ge WP, Huang W, He Y, Wang GX, Rowson-Baldwin A, Smith SJ, Jan YN, Jan LY (2011) Bidirectional regulation of dendritic voltagegated potassium channels by the fragile $\mathrm{X}$ mental retardation protein. Neuron 72:630-642. CrossRef Medline

LiX, Bennett DJ (2007) Apamin-sensitive calcium-activated potassium currents (SK) are activated by persistent calcium currents in rat motoneurons. J Neurophysiol 97:3314-3330. CrossRef Medline

Lu U, Roach SM, Song D, Berger TW (2012) Nonlinear dynamic modeling of neuron action potential threshold during synaptically driven broadband intracellular activity. IEEE Trans Biomed Eng 59:706-716. CrossRef Medline

Myrick LK, Deng PY, Hashimoto H, Oh YM, Cho Y, Poidevin MJ, Suhl JA, Visootsak J, Cavalli V, Jin P, Cheng X, Warren ST, Klyachko VA (2015) Independent role for presynaptic FMRP revealed by an FMR1 missense mutation associated with intellectual disability and seizures. Proc Natl Acad Sci U S A 112:949-956. CrossRef Medline

Routh BN, Johnston D, Brager DH (2013) Loss of functional A-type potassium channels in the dendrites of CAl pyramidal neurons from a mouse model of fragile X syndrome. J Neurosci 33:19442-19450. CrossRef Medline

Routh BN, Rathour RK, Baumgardner ME, Kalmbach BE, Johnston D, Brager $\mathrm{DH}$ (2017) Increased transient $\mathrm{Na}(+)$ conductance and action potential output in layer $2 / 3$ prefrontal cortex neurons of the fmr1 $(-/ y)$ mouse. J Physiol 595:4431-4448. CrossRef Medline

Santoro MR, Bray SM, Warren ST (2012) Molecular mechanisms of fragile X syndrome: a twenty-year perspective. Annu Rev Pathol 7:219-245. CrossRef Medline

Schaeffer C, Bardoni B, Mandel JL, Ehresmann B, Ehresmann C, Moine H (2001) The fragile X mental retardation protein binds specifically to its mRNA via a purine quartet motif. EMBO J 20:4803-4813. CrossRef Medline

Schulz R, Kirschstein T, Brehme H, Porath K, Mikkat U, Köhling R (2012) Network excitability in a model of chronic temporal lobe epilepsy critically depends on SK channel-mediated AHP currents. Neurobiol Dis 45: 337-347. CrossRef Medline

Siomi H, Siomi MC, Nussbaum RL, Dreyfuss G (1993) The protein product of the fragile $\mathrm{X}$ gene, FMR1, has characteristics of an RNA-binding protein. Cell 74:291-298. CrossRef Medline

Siomi H, Choi M, Siomi MC, Nussbaum RL, Dreyfuss G (1994) Essential role for $\mathrm{KH}$ domains in RNA binding: impaired RNA binding by a mutation in the $\mathrm{KH}$ domain of FMR1 that causes fragile $\mathrm{X}$ syndrome. Cell 77:33-39. CrossRef Medline

Stackman RW, Hammond RS, Linardatos E, Gerlach A, Maylie J, Adelman JP, Tzounopoulos T (2002) Small conductance Ca2+-activated K+ channels modulate synaptic plasticity and memory encoding. J Neurosci 22: 10163-10171. CrossRef Medline

Strumbos JG, Brown MR, Kronengold J, Polley DB, Kaczmarek LK (2010) Fragile $\mathrm{X}$ mental retardation protein is required for rapid experiencedependent regulation of the potassium channel Kv3.1b. J Neurosci 30: 10263-10271. CrossRef Medline

Xia XM, Fakler B, Rivard A, Wayman G, Johnson-Pais T, Keen JE, Ishii T, Hirschberg B, Bond CT, Lutsenko S, Maylie J, Adelman JP (1998) Mechanism of calcium gating in small-conductance calcium-activated potassium channels. Nature 395:503-507. CrossRef Medline 
Yamada-Hanff J, Bean BP (2013) Persistent sodium current drives conditional pacemaking in CA1 pyramidal neurons under muscarinic stimulation. J Neurosci 33:15011-15021. CrossRef Medline

Yang YM, Arsenault J, Bah A, Krzeminski M, Fekete A, Chao OY, Pacey LK, Wang A, Forman-Kay J, Hampson DR, Wang LY (2018) Identification of a molecular locus for normalizing dysregulated GABA release from interneurons in the Fragile X brain. Mol Psychiatry. Advance online publication. Retrieved Nov. 2, 2018. CrossRef Medline

Zang JB, Nosyreva ED, Spencer CM, Volk LJ, Musunuru K, Zhong R, Stone EF, Yuva-Paylor LA, Huber KM, Paylor R, Darnell JC, Darnell RB (2009) A mouse model of the human Fragile X syndrome I304N mutation. PLoS Genet 5:e1000758. CrossRef Medline
Zhang Y, Huang H (2017) SK channels regulate resting properties and signaling reliability of a developing fast-spiking neuron. J Neurosci 37: 10738-10747. CrossRef Medline

Zhang Y, Brown MR, Hyland C, Chen Y, Kronengold J, Fleming MR, Kohn AB, Moroz LL, Kaczmarek LK (2012) Regulation of neuronal excitability by interaction of fragile $\mathrm{X}$ mental retardation protein with slack potassium channels. J Neurosci 32:15318-15327. CrossRef Medline

Zhang Y, Bonnan A, Bony G, Ferezou I, Pietropaolo S, Ginger M, Sans N, Rossier J, Oostra B, LeMasson G, Frick A (2014) Dendritic channelopathies contribute to neocortical and sensory hyperexcitability in $\operatorname{Fmrl}(-/ y)$ mice. Nat Neurosci 17:1701-1709. CrossRef Medline 